\title{
LA EVOLUCIÓN DEL EMPLEO EN EL SECTOR FERROVIARIO ESPAÑOL, $1893-1935^{1}$
}

\author{
ESMERALDA BALLESTEROS DONCEL \\ TOMÁS MARTÍNEZ VARA
}

Escuela Universitaria de Estudios Empresariales

Universidad Complutense de Madrid

\section{RESUMEN}

En este trabajo se presenta una estimación inédita sobre la oferta de empleo en el sector ferroviario español entre 1893 y 1935 . Los datos anuales publicados por el conocido Anuario de los Ferrocarriles han sido minuciosamente depurados y contrastados con documentación relativa a las dos grandes compañías: Norte y MZA. Los resultados confirman la bondad de la fuente y realzan el enorme dinamismo de este peculiar mercado de trabajo: las cifras de empleo se triplicaron entre 1893 y 1935 . La documentación analizada pone de manifiesto además la existencia de un mercado de trabajo segmentado.

\section{ABSTRACT}

This article is a novel study on previously unedited data regarding employment in the Spanish Railway sector between the years 1893-1935. The Annual data published by the well know Annals of the Spanish Railways have been closely scrutinised and checked against document referring to the two major companies: Norte y MZA. The resulting findings show the dynamic nature of this labour market! Between 1893 and 1935 employment figures tripled. The documents examined further reveal the existence of a labour market which was quite diverse and consisted of numerous different segments.

$N$. de E.: Fecha de recepción del artículo en la Revista de Historia Económica: octubre de 2000 .

Fecha de aprobación por el Consejo de Redacción: noviembre de 2001. financiado por la Consejería de Educación y Cultura de la Comunidad Autónoma de Madrid. 


\section{INTRODUCCIÓN}

Como no podía ser de otro modo, los más eminentes historiadores han dedicado al estudio de la historia del ferrocarril gran atención y han polemizado entre ellos acerca del papel que cabe atribuir al ferrocarril en el desarrollo económico del país ${ }^{2}$. Ahora bien, la eclosión de trabajos de carácter económico, magníficos muchos de ellos, contrasta con la escasez de estudios donde se trate la gestión empresarial o las relaciones laborales en dichas empresas ${ }^{3}$. El análisis del empleo en las compañías ferroviarias ha sido sistemáticamente soslayado. Se desconoce el volumen de la oferta de trabajo del sector, no ya en los inicios de la construcción, lo que es comprensible, sino incluso cuando la red ya se había consolidado y se estaba iniciando el trasvase de efectivos del sector agrario hacia la industria y los servicios.

El objetivo de estas páginas es rellenar en parte ese hueco. Se ha realizado una estimación en base a las cifras publicadas en el Anuario de Ferrocarriles Españoles, sometiendo a contraste los resultados con otras fuentes de naturaleza empresarial. El análisis de los datos revela que la iniciativa empredida por Enrique de la Torre al editar un documento estadístico que recogiera los aspectos más relevantes de las distintas compañías fue más que meritorio. La excepcionalidad del Anuario es que en una misma fuente encontramos, año a año y compañía por compañía, el volumen de trabajo contratado. Es más, sin esta estadística cualquier intento de aproximación cuantitativa a la evolución del empleo en el sector está abocado al fracaso, ya que la documentación de la mayoría de las pequeñas concesionarias no está disponible, y la clasificación de actividad económica que ofrecen los censos de población es realmente deficitaria. Las series resultantes arrancan en el último decenio del siglo pasado y concluyen momentos antes del estallido de la guerra civil. La estadística del empleo en la red de vía ancha se enlaza con la que, a partir de la nacionalización de los ferrocarriles y hasta los años noventa de nuestro siglo, elaboró Muñoz (1995, p. 327), disponiendo así de la tendencia secular del empleo en el sector ferroviario español.

2 Conocidas son las ya lejanas tesis de Nadal (1975), Tortella (1973), Cordero y Menéndez (1978), Tedde (1978) y Rafael Anes (1978), las posteriores de Antonio Gómez Mendoza (1982) y las más recientes de Comin, Martín Aceña, Muñoz Rubio y Vidal Olivares (1998), con el mérito, además, de cubrir prácticamente todo el periodo de vida del ferrocarril.

"Son excepción los recientes trabajos de Vidal Olivares (1999) y Ortúnez (1999). Para el periodo anterior a la constitución de Renfe, sólo disponemos de las referencias de Soto Carmona (1989) y de los estudios de Juez Gonzalo (1992) y (2000). 


\section{EL ANUARIO DE FERROCARRILES ESPAÑOLES COMO FUENTE}

Las primeras compañías ferroviarias están consideradas como el antecedente de la empresa corporativa moderna, caracterizada por su gran tamaño y su compleja organización y, en consecuencia, por sus elevados costes fijos. La necesidad de coordinar, controlar y evaluar un conjunto disperso y diverso de unidades operativas propició la presencia de directivos especializados en administración y gestión empresarial, surgiendo un nuevo quehacer profesional conocido como management.

En España y durante los primeros años de la explotación, los consejos de administración de las grandes compañías centralizaron en sus manos, entre otros aspectos, la dirección general de las plantillas, siendo competencia suya decidir los nombramientos, traslados y ascensos de sus agentes. Así, las actas de dicho órgano se revelan como la primera fuente para el conocimiento de las condiciones de trabajo de los empleados, teniendo constancia de que, además, fueron numerosos y, a menudo, bastante meticulosos los informes generados sobre esta materia ${ }^{4}$. Otra cosa muy distinta es que la documentación conservada, o al menos la hasta ahora disponible, sea escasa, fragmentaria y discontinua.

En febrero de 1858, con sólo 455 kilómetros de red, el Consejo de Administración de MZA - Compañía de los Ferrocarriles de Madrid a Zaragoza y Alicante- aprueba la plantilla nominal que habría de regir a partir del mes siguiente; estaría integrada por 792 plazas, de las que, en ese momento, ya se habían cubierto 603. No aparecen contabilizados los trabajadores a jornal y el personal suplementario que, como mínimo, representaría otro tanto ${ }^{5}$. Algo más tarde, en 1865, Norte -Compañía de los Caminos de Hierro del Norte de España-, con 752 kilómetros en explotación, señala una plantilla de 3.409 agentes — según las Actas de su CA- Lamentablemente, estas cifras proporcionan datos inconexos, sin la necesaria continuidad y muy poco representativos de lo que acabarán siendo en el futuro las plantillas reales de ambas compañías.

4 En marzo de 1859 el Consejo de Administración de MZA, a instancias de la Comisión de Cuentas, acuerda: 1) que el servicio de Contabilidad lleve un libro exclusivamente de todo el personal de la Compañía; 2) que desde la Dirección se facilite a la Contabilidad toda la información necesaria para la confección de dicho libro, y 3) que se notifiquen ascensos, traslados, ceses y nombramientos. ACA, 4 de marzo de 1859.

'ACA, 14 de enero, 24 de febrero, 26 de febrero y 22 de marzo de 1858 . Juez Gonzalo estima que el total de la plantilla, sin incluir los jornaleros y suplementarios del Servicio de Tracción, supondría unos 1.612 agentes (1992, pp. 102-104). 
En 1893, diseñada y construida ya la red principal, aparece una obra excepcional, el Anuario de Ferrocarriles Españoles. Su autor, Enrique de la Torre, se proponía facilitar cada año, al estilo de los Manual Poor americanos, todo lo que a ferrocarriles se refiere, sintetizando un gran volumen de información demandada a las compañías ${ }^{6}$. La respuesta fue, en principio, mejor de lo que cabía esperar. Un año después de la publicación del primer número, De la Torre expresaba su gratitud a los directores de las principales compañías por su colaboración en el presto envío de datos ${ }^{7}$. Pero lo cierto es que fueron muchas las que, aun funcionando ya sus líneas ferroviarias con toda regularidad, hicieron caso omiso de la petición. Algunas de ellas, especialmente las más pequeñas y en particular las de vía estrecha, o bien por recelo o simplemente por desidia, se tomaron varios años antes de comenzar a remitir la correspondiente información.

En materia de empleo, la estadística suministrada por el Anuario es desigual y asimétrica. En el caso de los jefes, y con independencia de su rango dentro las compañias, se ofrecen relaciones nominales a partir de la categoría de jefes de estación; con el resto de los trabajadores, en cambio, la situación es menos prolija. Mientras algunas compañías (es el caso de MZA, MCP - Compañía de los Ferrocarriles de Madrid a Cáceres y Portugal—, TBF — Compañía de los Ferrocarriles de Tarragona a Barcelona y Francia - o Andaluces) muestran el número de agentes por servicios, otras, en cambio, sólo indican el total sin ningún tipo de matizaciones. Que el repertorio de profesiones mostrado sea más amplio denota mayores niveles de información, pero en absoluto significa que ésta sea más cabal, al menos por lo que a la cifra total de agentes se refiere. Hubo compañias que remitieron notas muy concisas, pero claras. El ferrocarril de Triano, por poner sólo un ejemplo, se cuidó mucho, quizá por su carácter minero, de que se distinguiera entre los «empleados fijos» de la compañía, cuyo montante indicó desde el primer momento, y los «operarios de talleres y de la carga y descarga de mineral», de los que, por tratarse de un número siempre variable, no se ofrecían datos. No hubo, en absoluto, convergencia

"Enrique de la Torre fue empleado del Servicio de Intervención y Estadistica en Norte y, más tarde, jefe de la Oficina de Tasas en la misma compañía; según él mismo confiesa, se sintió orgulloso de ser ferroviario (1902: IV). En 1905 figura como secretario de la Asociación General del Empleados y Obreros de los Ferrocarriles, organización a la que criticará años después por su proceder gremialista y su falta de sensibilidad social, Anuario (1912, pp. xxiii-xxiv). Publicó varios libros, todos ellos con un carácter eminentemente práctico, aunque su gran obra fue sin lugar a dudas el Anuario de Ferrocarriles Españoles, declarada con toda justicia de utilidad general (RO de 24 de octubre de 1894).

${ }^{7}$ Anuario de los Ferrocarriles (1893, p. 10). 
alguna de criterios entre las compañías a la hora de señalar la población empleada. Desconocemos, asimismo, si la Dirección del Anuario remitió a las compañías algún tipo de directriz. Esta circunstancia obliga a ser cautos y desaconseja comparaciones entre servicios y profesiones de las diferentes concesionarias.

No es infrecuente, por otro lado, que una misma compañía cambie de norma a lo largo del tiempo - Norte ${ }^{8}$ - o suspenda de manera transitoria los envíos - Ferrocarriles de Mallorca ${ }^{9}$ - , sin que en ambos casos sepamos el porqué. Las fusiones también pueden crear cierta desorientación durante algún tiempo. Veamos un ejemplo. En 1906 se fusionan las Compañías de los Ferrocarriles Central de Vizcaya de Bilbao a Durango, de Durango a Zumárraga y de Elgóibar a San Sebastián, dando lugar a la Compañía Ferrocarriles Vascongados; el número total de empleados que remitió la nueva compañía un año después se elevó a 741, una cifra corta en relación con los datos que con anterioridad habían venido ofreciendo las concesionarias ahora fusionadas. Al no disponer de otra información, hemos de aceptar dicha cifra ${ }^{10}$. Es necesario también tener sumo cuidado con la información de las líneas que pasan a depender de la Jefatura de Explotación de Ferrocarriles del Estado, organismo creado en 1926, porque, a menudo, no se distingue entre los trabajadores que operan en los ferrocarriles de vía ancha y los que lo hacen en los de vía estrecha.

En todo caso, éstos son problemas menores y afectaron a un número reducido de líneas de carácter secundario, con muy poca incidencia en los cómputos generales. La principal ventaja que posee el Anuario de Ferrocarriles Españoles como fuente para evaluar la oferta de empleo del sector

${ }^{8}$ En 1894, y después de ofrecer una información del personal muy detallada, distinguiendo servicios, añade: «No se indica el número de agentes de la explotación en las Estaciones, por ser muy variable: próximamente (sic) se eleva a 3.400 en junto; de manera que puede calcularse a la Compañia del Norte 11.200 empleados en números redondos», sin contar los obreros de sus minas (Barruelo y Surroca), Anuario de Ferrocarriles (1894, p. 84). En adelante, sólo mencionará el total de efectivos sin especificar si incluye o no el personal de las estaciones. No deja de sorprender que siendo Enrique de la Torre empleado de Norte la información remitida por ésta sea tan escueta.

${ }^{9}$ Ésta es una de las compañías que enviaron la información de forma más errátil

Desgraciadamente la ambiciosa monografia de Brunet (1994) no resuelve el problema, pues sólo indica el número de agentes para dos años, 1925 y 1938.

${ }^{10}$ Según Ormaechea (1989, pp. 513.526, 454 y 490), en el Ferrocarril de Durango a Zumárraga trabajaban, en 1899, 184 empleados, 215 en 1900, 279 en 1901 y 316 en 1902 (las cifras son muy similares a las ofrecidas por el Anuario). El de Elgóibar a San Sebastián emplea, en 1900, 370 agentes y, en 1901, 478. Si a estos guarismos se suman los del otro ferrocarril que entra en la fusión, el Central de Vizcaya, sorprende que el Anuario ofrezca, para los años 1907-1909, 741 empleados como promedio. 
es que, desde su aparición en 1893 y hasta el estallido de la guerra civil, suministra, año a año, información puntual sobre el empleo en prácticamente todas las concesionarias. Tan sólo faltan los datos relativos a 1929 y 1932, problema menor porque, como luego se verá, para ese momento existe información alternativa de toda solvencia en el caso de las grandes. El nudo gordiano de la cuestión estriba, sin embargo, en dilucidar si los guarismos del Anuario contienen o no la totalidad de activos, es decir, si sus cómputos son o no fidedignos. Para esclarecer esta cuestión se analizan, siguiendo la documentación empresarial, la evolución del empleo en las dos compañías líderes - Norte y MZA - y se contrastan los resultados con los ofrecidos por el Anuario para determinar su bondad.

\section{El empleo en la Compañía de los Caminos de Hierro del Norte de España}

La evolución del empleo en Norte puede seguirse a través del Anuario desde 1894; a las lagunas generales de los años 1929 y 1932 hay que añadir las propias de 1895 y $1905^{11}$. Conviene advertir también que, durante los primeros años, se repiten a menudo los guarismos (1896-1900, 1901-1904 y 1906-1907). La información publicada permite conocer el cómputo global de sus agentes y el detalle de los trabajadores ocupados en los talleres principales de Valladolid ${ }^{12}$.

La serie resultante (Tabla 1, columna 3) puede ser contrastada con otras informaciones provenientes de la misma empresa. En 1940 Marquina, antiguo director de la compañía y primer presidente de Renfe, proporciona una serie de empleo de Norte entre 1906 y $1935^{13}$ (Tabla 1, columna 2). Por su condición, debía conocer muy bien las fuentes, aunque desgraciadamente no menciona las que utilizó ni aclara los criterios que siguió para su elaboración. La comparación de ambas series pone de manifiesto

"La laguna relativa al año 1929 fue justificada por Enrique de la Torre: cuando en 1928 estaba a punto de salir el Anuario surgió la Compañia Nacional de los Ferrocarriles del Oeste de España, integrando varias líneas que hasta entonces se explotaban independientemente por el Estado y por empresas particulares con un total de 1.587 kilómetros. De haber salido entonces el Anuario no hubiera podido registrar los cambios producidos.

${ }^{12}$ Norte consideró a Valladolid como el punto más importante de toda la explotación de su red y allí estableció el Taller Principal de reparaciones de locomotoras y material móvil de la compañía, reuniendo un número importante de operarios cuya evolución y condiciones de trabajo ha estudiado Pérez Sánchez (1992).

${ }_{13}$ Marquina (1940, II, cuadro 38). 
TABLA 1

Trabajadores de la Compañia de los Caminos de Hierro del Norte de España, seguin distintas fuentes, 1894-1935

\begin{tabular}{|c|c|c|c|c|c|}
\hline Año & $\begin{array}{c}\text { Personal } \\
\text { de plantilla }\end{array}$ & Marquina & Anuario & $\begin{array}{l}\text { Relaciones } \\
\text { de personal }\end{array}$ & $\begin{array}{c}\% \text { de la plantilla } \\
\text { sobre total de } \\
(1) /(3) * 100\end{array}$ \\
\hline & (1) & $(2)$ & (3) & (4) & (5) \\
\hline $1894 \ldots \ldots \ldots \ldots \ldots$ & & & 11.200 & & \\
\hline $1895 \ldots \ldots \ldots \ldots \ldots . . . . . . . .$. & & & 19.185 & & \\
\hline $1896 \ldots \ldots \ldots \ldots \ldots$ & & & 19.185 & & \\
\hline 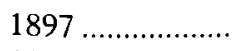 & & & 19.185 & & \\
\hline $1898 \ldots \ldots \ldots \ldots \ldots$ & 6.705 & & 19.185 & & 34,94 \\
\hline 1899 & & & 19.185 & & \\
\hline $1900 \ldots \ldots \ldots \ldots \ldots$ & 6.963 & & 19.185 & & 36,29 \\
\hline $1901, \ldots \ldots \ldots \ldots \ldots$ & 7.136 & & 23.132 & & 30,98 \\
\hline $1902 \ldots \ldots \ldots \ldots \ldots$ & 7.473 & & 23.132 & & 32,12 \\
\hline $1903 \ldots \ldots \ldots \ldots \ldots$ & & & 23.132 & & \\
\hline $1904 \ldots \ldots \ldots \ldots \ldots$ & 7.677 & & 23.132 & & 32,75 \\
\hline $1905 \ldots \ldots \ldots \ldots \ldots$ & 7.685 & & 23.132 & & 33,22 \\
\hline $1906 \ldots \ldots \ldots \ldots \ldots$ & & 18.280 & 22.965 & & \\
\hline 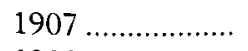 & 8.146 & 18.662 & 22.965 & & 35,47 \\
\hline $1908 \ldots \ldots \ldots \ldots \ldots$ & 8.295 & 19.527 & 22.892 & & 36,23 \\
\hline 1909 ......................... & 8.426 & 20.128 & 25.605 & & 32,90 \\
\hline $1910 \ldots \ldots \ldots \ldots \ldots$ & 8.566 & 20.812 & 25.641 & & 33,40 \\
\hline $1911 \ldots \ldots \ldots \ldots \ldots$ & 8.641 & 21.902 & 26.124 & & 33,07 \\
\hline $1912 \ldots \ldots \ldots \ldots \ldots$ & 9.242 & 23.218 & 26.210 & & 35,26 \\
\hline $1913 \ldots \ldots \ldots \ldots \ldots$ & 10.346 & 25.705 & 26.226 & 25.705 & 39,45 \\
\hline $1914 \ldots \ldots \ldots \ldots \ldots$ & 10.474 & 27.015 & 26.792 & & 39,09 \\
\hline $1915 \ldots \ldots \ldots$ & 10.978 & 27.754 & 28.450 & & 38,58 \\
\hline $1916 \ldots \ldots \ldots \ldots \ldots$ & 10.984 & 29.972 & 29.719 & & 36,95 \\
\hline $1917 \ldots \ldots \ldots \ldots \ldots$ & 11.027 & 31.188 & 30.983 & 30.935 & 35,59 \\
\hline $1918 \ldots \ldots \ldots \ldots \ldots$ & 11.452 & 31.687 & 30.916 & 31.453 & 37,04 \\
\hline $1919 \ldots \ldots \ldots \ldots \ldots$ & 11.482 & 31.960 & 31.471 & & 36,48 \\
\hline $1920 \ldots \ldots \ldots \ldots \ldots$ & 11.503 & 34.177 & 31.471 & 31.355 & 36,55 \\
\hline $1921 \ldots \ldots \ldots \ldots \ldots$ & 12.007 & 35.154 & 31.114 & & 38,59 \\
\hline $1922 \ldots \ldots \ldots \ldots \ldots$ & 12.226 & 35.014 & 34.114 & & 35,85 \\
\hline $1923 \ldots \ldots \ldots \ldots \ldots$ & 12.232 & 36.050 & 34.114 & & 35,85 \\
\hline $1924 \ldots \ldots \ldots \ldots \ldots$ & 12.399 & 36.576 & 34.114 & & 36,34 \\
\hline $1925 \ldots \ldots \ldots \ldots \ldots$ & 12.643 & 38.264 & 34.160 & & 37,15 \\
\hline $1926 \ldots \ldots \ldots \ldots \ldots$ & 14.413 & 39.234 & 34.160 & & 42,19 \\
\hline $1927 \ldots \ldots \ldots \ldots \ldots$ & 14.542 & 39.221 & 40.789 & & 35,65 \\
\hline $1928 \ldots \ldots \ldots \ldots . . . . . . .$. & 14.635 & 39.886 & 40.800 & & 35,87 \\
\hline
\end{tabular}


TABLA 1 (Cont.)

Trabajadores de la Compañia de los Caminos de Hierro del Norte de España, seguin distintas fuentes, 1894-1935

\begin{tabular}{|c|c|c|c|c|c|}
\hline Año & $\begin{array}{c}\text { Personal } \\
\text { de plantilla }\end{array}$ & Marquina & Anuario & $\begin{array}{l}\text { Relaciones } \\
\text { de personal }\end{array}$ & $\begin{array}{l}\% \text { de la plantilla } \\
\text { sobre total de } \\
(1) /(3) * 100\end{array}$ \\
\hline & (1) & (2) & (3) & (4) & (5) \\
\hline $1929 \ldots \ldots \ldots \ldots \ldots$ & 14.765 & 40.418 & 40.800 & & 36,18 \\
\hline $1930 \ldots \ldots \ldots \ldots \ldots$ & 15.010 & 42.601 & 40.800 & & 36,78 \\
\hline $1931 \ldots \ldots \ldots \ldots \ldots$ & 15.199 & 42.536 & 42.601 & & 35,67 \\
\hline $1932 \ldots \ldots \ldots \ldots \ldots$ & 15.465 & 42.430 & 42.601 & & 36,30 \\
\hline $1933 \ldots \ldots \ldots \ldots \ldots$ & 16.267 & 42.583 & 42.430 & & 38,33 \\
\hline $1934 \ldots \ldots \ldots \ldots \ldots . . . . . . . .$. & 16.384 & 42.788 & 42.583 & & 38,47 \\
\hline $1935 \ldots \ldots \ldots \ldots \ldots$ & 15.458 & 41.035 & 42.788 & & 36,12 \\
\hline
\end{tabular}

Fuentes: (1) Expedientes de Personal de Norte, legs. 117 y 118, y Norte (1916, p. 39); (2) Marquina (1940, II, cuadro 38); (3) Anuario de Ferrocarriles, 1893-1935; (4) Relaciones Numéricas del personal de plantilla y jornalero de las Compañias Norte y MZA (S. L.: S. N.), 1913, AHF: C/3/27 y C/58/41.

divergencias entre ellas en dos tramos cronológicos, 1906-1912 y 1920-1926.

En los siete primeros años, la relación de Marquina discrepa en promedio de la del Anuario en unos 5.000 agentes. Lo mismo sucede entre 1920 y 1926, pero en este caso es el Anuario quien se sitúa por debajo de los datos de Marquina. El hecho de que la magnitud de las diferencias sea similar en los dos momentos hace sospechar de que alternativamente las fuentes han ignorado algún colectivo de personal. Probablemente se trate de los suplementarios y trabajadores de las minas de Barruelo y Surroca. A partir de 1927 desaparecen las repeticiones injustificadas en el Anuario, responsables del perfil en escalones que presenta la curva, y ambas series vuelven a encontrarse y caminar al unísono.

Para entender las disparidades entre las cifras es necesario aclarar cómo se construyen las estadísticas del empleo. A través de la Instrucción General Núm. 2 de Norte, emitida en 1891, sabemos que la compañía tenía establecidos dos tipos de personal estable: personal de plantilla y personal 
a jornal ${ }^{14}$. Los agentes de plantilla ocupaban los mejores puestos, eran los mejor pagados ${ }^{15}$ y disfrutaban de todas las ventajas concedidas por la empresa (Tabla 1, columna 1). Desde fechas tan tempranas como enero de 1873 , tuvieron derecho a retiro, viudedad y orfandad siempre que llevaran un determinado tiempo en la compañía. Su importancia numérica en la empresa representó algo más de un tercio de la contratación total (Tabla 1, columna 5).

El personal a jornal fue siempre más numeroso, aunque sus ingresos medios eran considerablemente inferiores y sus prestaciones también menores. Por ejemplo, no se les concedió derecho a pensión hasta enero de 1913, siendo una de las revindicaciones de la huelga general de $1912^{16}$. Según la misma Instrucción, este grupo lo componían: 1) los individuos admitidos temporalmente en las oficinas de los servicios centrales y en las estaciones para hacer trabajos extraordinarios; 2) los individuos admitidos a prueba o como auxiliares; 3) los obreros o mozos que forman parte de una brigada y están encargados de las maniobras de trenes y vagones, de la carga y descarga de mercancías, de la conservación o limpieza de coches y vagones; 4) los de los talleres, depósitos y almacenes, los capataces, obreros, guardas y guardesas de las vías, así como los trabajadores de las minas.

Existió, además del personal estable, un grupo de trabajadores denominados «personal auxiliar» que no pertenecía a la empresa, pero que era contratado eventualmente. La compañía mostró una gran resistencia a integrar a estos trabajadores como personal a jornal y ello por dos razones. Por un lado, para evitar el incremento de los costes fijos de personal y, por otro lado, por la propia cultura corporativa de las empresas ferroviarias que les consideraba obreros, «sin más preparación ni estudio que los nece-

${ }^{14}$ Instrucción General Núm. 2, AHF, C/50/17. Véanse también Juez Gonzalo (1992, pp. 68-74) y Pérez Sánchez (1992, pp. 265-266). En 1916 Norte publica un estudio comparando los salarios de sus empleados con los del resto de las industrias; en él se divide a los por trabajo puramente corporal en talleres, minas, estaciones a todo aquel quación y movimiento (jefes de estación, factores, maquinistas, etc.) via), personal de explas Ante las demandas crecientes de los trabajadores, Norte formó en y personal de oficinas. Ante las de revisaran los contenidos de la mencionada Instrucción 1918 una comisión para que se revisaras fueron, sin embargo, muy pocas, Norte (1920). Núm. 2; las modificaciones introducidas 10.246 miembros de plantilla en 1913 ascendió

${ }^{15}$ El importe de los sueldos de los 10.246 mijos fue de 13.602 .961 , lo que suponen a 16.886.748 reales y el de los 15.359 jornalectivamente. Relaciones Numéricas de personal, 1913.

${ }_{16}$ Instituto de Reformas Sociales (1913, pp. 92-93). 
sarios para aprender a trabajar en su oficio o arte» ${ }^{17}$. La Instrucción General Núm. 2 señala con respecto a ellos: «sólo se propondrán auxiliares en caso de necesidad absoluta [...], debiendo ser dados de baja en cuanto desaparezca la necesidad», y se instaba a los inspectores para que se mostraran muy escrupulosos al respecto.

En 1905 el director de Norte va a definirse claramente en la polémica sobre la regularización o la definitiva separación de la compañía del «personal auxiliar», manifestando que, en su opinión, sería imposible prescindir del mismo debido a las necesidades del servicio y justifica la conveniencia de contratarlo de forma permanente por dos motivos: 1) es imposible prescindir de su concurso, y 2) los empleados fijos, «que tienen derechos reconocidos en los reglamentos, incluso el de jubilación, prestan en general mucho mejor servicio que los auxiliares, por lo mismo se les puede exigir más responsabilidad que á estos últimos» ${ }^{18}$. La falta de criterios comunes en la consideración de estos auxiliares es lo que hace que no se incluyan siempre en las estadísticas de empleo de la propia compañía. Creemos que el cómputo o no de este heterogéneo y abigarrado personal es, con toda probabilidad, una de las causas de que las cifras fluctúen de unas fechas a otras.

Existen cuatro monografías relativas a los años 1913, 1917, 1918 y 1920 en la que se ofrecen relaciones precisas del personal al servicio de Norte (Tabla 1, columna 4) ${ }^{19}$. Para el año 1913 el documento es muy interesante porque incluye conjuntamente los datos de Norte y MZA y, además, clasifica a todos los agentes por oficio y sueldo ${ }^{20}$. De los 25.705 individuos a que asciende el empleo total, 10.346 corresponden a la plantilla -dato que coincide con el insertado para ese mismo año en columna 1 de la Tabla 1-y el resto son jornaleros fijos. Están incluidos los 2.009 mozos suplementarios y los 832 trabajadores de las minas de Barruelo y Surroca, esto es, unos 3.000 agentes. La suma total coincide con la que ofrece Marquina y difiere muy poco de la del Anuario, lo que refuerza la fiabilidad de ambas en ese momento.

Las relaciones de personal relativas a 1917,1918 y 1920 carecen del detalle de la de 1913, pero sí explican, en cambio, el motivo de su ela-

17 Norte (1916).

${ }^{18}$ AHF, Expedientes de Personal de Norte, legs. 117 y 118.

19 En la obra Antecedentes y datos para el estudio del problema ferroviario (1940, IV, p. 122), el Ministerio de Obras Públicas publicó series de empleo ferroviario referidas a Norte, MZA, Andaluces y Oeste para el período 1929-1935. Por lo que se refiere a Norte las cifras son prácticamente idénticas a las de Marquina.

${ }^{20}$ Relaciones numéricas del personal, 1913. 
boración. En plena crisis ferroviaria y ante la inminente implantación de la jornada de las ocho horas, las dos grandes concesionarias, Norte y MZA, deciden unificar criterios a la hora de actuar. A tal efecto, sus directores, Félix Boix y Eduardo Maristany, intercambian información sobre los resultados de la explotación obtenidos en el difícil período 1913-1919, especialmente los costes laborales. Según dicha información, en 1919 trabajaban en Norte 31.453 agentes, incluyendo los 3.025 suplementarios de las estaciones. No están contabilizados y esto es lo que aquí interesa resaltar: «los jornaleros que se toman en algunas ocasiones en número muy variable [...]; el personal de los contratistas de carga, descarga y removido en las estaciones en que este servicio se halla contratado (unos 800 agentes); los obreros encargados de la carga de carbón en los ténderes, en los depósitos en que este servicio se halla contratado (unos 850); y los obreros de todas clases empleados en obras de carácter extraordinario y complementario, como renovación de vía, nuevas estaciones, dobles vías, etc., en número muy variable» ${ }^{21}$. Estas consideraciones confirman las sospechas de que el personal «auxiliar», contratado eventualmente en distintas faenas, representa un volumen de empleo nada despreciable; su omisión de las estadísticas del personal pudiera estar reflejando las expectativas de la dirección de la compañía de prescindir a corto y medio plazo del mismo, pero la realidad es que su participación siguió siendo necesaria. Para Norte, pues, la serie que se deduce del Anuario, corregida para el período 1920-1926 con la información proporcionada por Marquina, es bastante consistente y tiene en cuenta el personal de plantilla, los jornaleros, los suplementarios y los empleados de las minas, aunque probablemente omita los obreros de las contratas y los temporeros ocupados en obras de carácter extraordinario.

El empleo en la Compañía de los Ferrocarriles de Madrid a Zaragoza y a Alicante

El Anuario de Ferrocarriles Españoles ofrece información muy completa en el caso de la compañía MZA, sin otros huecos que los generales de 1929 y 1932. Los datos aparecen desagregados por servicios, distinguiendo, además, el personal ocupado en las minas (Tabla 2, columnas 1 y 2). El contraste de la serie se ha establecido con los Libros de Presupuestos de

${ }^{21}$ AHF: C/3/27. 


\section{TABLA 2}

Trabajadores de la Compañia de Madrid a Zaragoza y a Alicante, según distintas fuentes, 1894-1935

\begin{tabular}{|c|c|c|c|c|c|}
\hline Año & $\begin{array}{l}\text { Anuario, } \\
\text { sin minas }\end{array}$ & $\begin{array}{l}\text { Anuario, } \\
\text { con minas }\end{array}$ & $\begin{array}{l}\text { Libros de } \\
\text { Presupuestos }\end{array}$ & $\begin{array}{l}\text { Relaciones } \\
\text { de personal }\end{array}$ & $\begin{array}{c}\text { Suplementarios } \\
\text { y jomaleros }\end{array}$ \\
\hline & (1) & (2) & (3) & (4) & (5) \\
\hline $1893 \ldots \ldots$ & & 14.336 & & & \\
\hline 1894 & & 14.174 & & & \\
\hline 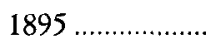 & & 14.868 & & & \\
\hline 1896 & & 10.050 & & & \\
\hline 1897 & & 14.449 & & & \\
\hline 1898 & & 14.692 & & & \\
\hline 1899 & & 14.903 & & & \\
\hline $1900 \ldots \ldots \ldots$ & & 14.232 & & & \\
\hline $1901 \ldots . . . . . . . . . . . . . .$. & & 15.730 & & & \\
\hline $1902 \ldots$ & & 15.794 & & & \\
\hline $1903 \ldots$ & & 16.585 & & & \\
\hline $1904 \ldots \ldots$ & 16.648 & 18.543 & & & \\
\hline $1905 \ldots \ldots \ldots \ldots \ldots$ & 17.081 & 18.976 & & & \\
\hline 1906 & 17.187 & 18.599 & & & \\
\hline 1907 ...................... & 18.879 & 20.265 & & & \\
\hline $1908 \ldots$ & 19.407 & 21.107 & & & \\
\hline 1909 & 19.483 & 21.297 & & & \\
\hline $1910 \ldots$ & 20.443 & 22.426 & 18.235 & & \\
\hline 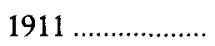 & 20.370 & 22.325 & 19.412 & & \\
\hline 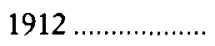 & 20.545 & 22.494 & 19.602 & & \\
\hline 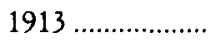 & 21.785 & 23.710 & 22.441 & $21.522(22.350)$ & \\
\hline 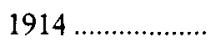 & 23.147 & 25.093 & 23.048 & 22.853 & \\
\hline $1915 \ldots$ & 21.876 & 23.822 & 22.772 & $22.757(21.696)$ & \\
\hline $1916 \ldots \ldots \ldots \ldots$ & 22.174 & 24.120 & 22.667 & $22.267(21.777)$ & \\
\hline 1917 & 22.226 & 24.172 & 22.641 & $22.683(22.168)$ & \\
\hline $1918 \ldots \ldots \ldots \ldots$ & 22.251 & 24.197 & 23.198 & 23.173 & \\
\hline 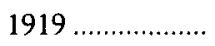 & 22.424 & 24.370 & 24.117 & 24.024 & 4.773 \\
\hline $1920 \ldots \ldots \ldots \ldots \ldots$ & 25.773 & 27.955 & 24.170 & 25.403 & 6.080 \\
\hline 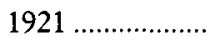 & 27.746 & 29.990 & 26.218 & 26.947 & 7.551 \\
\hline $1922 \ldots \ldots$ & 29.577 & 31.732 & 26.679 & 28.516 & 8.489 \\
\hline 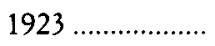 & 30.387 & 32.394 & 27.369 & 27.942 & 8.654 \\
\hline 1924 & 30.943 & 32.937 & 27.516 & 28.054 & 9.956 \\
\hline 1925 & 31.372 & 33.266 & 27.757 & 28.519 & 11.043 \\
\hline 1926 & 31.585 & 33.457 & 29.715 & 30.019 & 7.818 \\
\hline 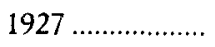 & 32.524 & 34.251 & 29.940 & 30.154 & 9.081 \\
\hline $1928 \ldots \ldots \ldots \ldots . . .$. & 32.534 & 34.264 & 30.557 & 30.642 & 9.630 \\
\hline
\end{tabular}


TABLA 2 (Cont.)

Trabajadores de la Compañia de Madrid a Zaragoza y a Alicante, seguin distintas fuentes, 1894-1935

\begin{tabular}{|c|c|c|c|c|c|}
\hline$A \tilde{n} o$ & $\begin{array}{l}\text { Anuario, } \\
\text { sin minas }\end{array}$ & $\begin{array}{l}\text { Anuario, } \\
\text { con minas }\end{array}$ & $\begin{array}{l}\text { Libros de } \\
\text { Presupuestos }\end{array}$ & $\begin{array}{l}\text { Relaciones } \\
\text { de personal }\end{array}$ & $\begin{array}{c}\text { Suplementarios } \\
\text { y jornaleros }\end{array}$ \\
\hline & (1) & (2) & (3) & (4) & (5) \\
\hline $1929 \ldots .$. & 32.534 & 34.264 & 31.224 & 31.374 & 8.968 \\
\hline $1930 \ldots \ldots \ldots \ldots$ & 31.978 & 36.120 & 31.784 & 31.915 & 7.018 \\
\hline $1931 \ldots \ldots \ldots \ldots$ & 31.737 & 33.603 & 32.133 & 32.113 & 4.296 \\
\hline $1932 \ldots \ldots \ldots \ldots \ldots$ & 31.737 & 33.603 & 33.692 & 31.818 & \\
\hline 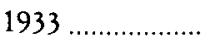 & 33.124 & 34.998 & 33.243 & 33.206 & 3.977 \\
\hline 1934 & 33.622 & 35.519 & 33.661 & 37.047 & \\
\hline 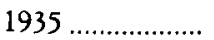 & 33.792 & 35.691 & 33.839 & 34.911 & 4.535 \\
\hline
\end{tabular}

Fuentes: (1) y (2) Anuario de los Ferrocarriles, 1893-1935; (3) Libros de Presupuestos de la MZA, 1910-1936 - no se incluye el personal de las minas-; (4) Relaciones Numéricas del personal de plantilla y jornaleros de las compañías Norte y MZA, entre paréntesis (1913) (S. L: S. N.); AHF: C/49/8, Datos sobre agentes en 1916, cifras entre paréntesis; AHF: $\mathrm{C} / 3 / 27$, Relaciones de datos de las compañías Norte y MZA. Remitidos por Maristany a Boix; para 1917 cifra entre paréntesis; AHF: $\mathrm{C} / 53 / 33, \mathrm{C} / 54 / 34$, Ventajas diversas de que disfruta el personal de los diferentes servicios (1913-1921) y (1921-1930), y MZA (1932 227, Cuadro 15); (5) MZA (1933 y 1935a)

la MZA (Tabla 2, columna 3), que ofrecen anualmente, además de la contabilidad empresarial, la estadística de los trabajadores por divisiones. La información parece bastante verosímil coincidiendo, a grandes rasgos, con la suministrada con los numerosos estudios, informes y notas generados a raíz del llamado «Problema Ferroviario» ${ }^{22}$.

Las diferencias observadas entre las cifras publicadas por el Anuario y los Presupuestos no son excesivas y en parte se pueden explicar porque en las estadísticas de personal de los Libros han suprimido las plantillas del llamado personal suplementario ${ }^{23}$.

${ }^{22}$ Se ha prescindido de todas las cifras en las que no consta la fuente; tampoco se han tenido en cuenta los datos de la prensa, obrera o patronal de carácter secundario, siempre proclive a magnificar o atemperar las estadísticas reales. Existe una interesante relación entre 1912 y 1916, en la que se indica un volumen de empleo de 16.828 en 1912, 18.614 en 1913, 19.569 en 1914, 18.589 en 1915 y 19.287 en 1916. Incluye sólo el personal de la Red Antigua y no consta la población minera [AHF: C/185/52, citado por Soto Carmona (1989, p. 160)].

${ }^{23}$ En 1909 la MZA inició una reorganización interna por la cual la contabilidad del 
Como sucediera en Norte, el Anuario discrepa de las Relaciones de Personal de 1913 en un porcentaje muy pequeño ${ }^{24}$, menos de un 3 por 100, y lo propio ocurre con las cifras correspondientes a los años 1915, 1916 y 1917 . Entre 1920 y 1930 los desajustes entre los valores sobre el empleo consignados en las fuentes son mayores. En este período, la serie que se deduce del Anuario se sitúa por encima de la extraída de los Presupuestos en un 6 por 100 como promedio, lo que en números absolutos representa una diferencia media de 2.395 agentes. Con toda probabilidad ello, como se indicará más adelante, obedece a la falta de rigor en la contabilidad del personal eventual ${ }^{25}$. En las notas intercambiadas por Maristany y Boix sobre los resultados de la explotación, el primero advierte de la necesidad de incrementar el volumen de la plantilla en 1.434 agentes, debido a la nueva política laboral ${ }^{26}$. No son, sin embargo, buenos tiempos de prognosis. Desde 1916 los gastos reales de la explotación superaron ampliamente la previsión de los presupuestos ${ }^{27}$; si en los primeros momentos la subida del precio del combustible y la adquisición de un material móvil más caro fueron responsables de tales desajustes ${ }^{28}$, a partir de 1919 lo fueron los costes laborales, en especial tras la implantación de la nueva legislación del trabajo sobre la reducción de la jornada laboral.

personal se descentralizó, asumiendo en adelante cada división la suya propia [Libros de Presupuestos (1910, pp. 1-3)]. Por esa misma razón, Coderch, subdirector de la Compañía, alerta sobre la existencia de posibles deficiencias en las plantillas anejas a los presupuestos, «ya que no permiten obtener datos seguros por falta de método y detalle» (AHF: C/49/4).

${ }^{24}$ En las discusiones mantenidas en el Senado sobre el proyecto de ley para obtener el aumento de las tarifas, un senador señaló que el número de agentes total al servicio de la MZA ascendía a 26.210 en 1913. La cifra parece exagerada, pero quizá no lo fuera tanto —y así lo indica con acierto Ortúnez (1999) - si en ella estuvieran incluidos el personal de minas, suplementario y de contrata, AHF: C/59/46.

${ }^{25}$ El Reglamento para la Contabilidad de los Servicios de la Red Antigua (1908) exigia una detallada estadística de todos los trabajadores eventuales mediante la elaboración de «listillas de jornales» u «hojas de tareas». También se advertía de la necesidad de despedir a los «obreros temporeros tan pronto se ultime el trabajo especial que haya motivado su contratación, "despidiéndoles en consecuencia". No debe consentirse el mantenimiento indefinido de este empleo, debiéndose proponer, si persiste la insuficiencia, la ampliación de la plantilla "cuanto fuera menester"» (MZA: 1908, pp. 8-10).

${ }^{26}$ Los 24.217 agentes previstos por Maristany para 1919 son los mismos que aparecen en los Presupuestos (libro 270: 44). La cifra se repite en otros documentos, AHF: C/58/37.

${ }^{27} \mathrm{La}$ diferencia porcentual entre lo presupuestado y lo gastado fue de un 25,8 por 100 para 1916 ; de 18,5 por 100 para 1917 ; de 23 por 100 para 1919 , y de 32,5 por 100 para 1920. Libros de Presupuestos correspondientes a los años 1920 y 1925.

${ }^{28}$ España Económica y Financiera, 19 de mayo y 9 de junio de 1917. El precio medio por tonelada de combustible pasó de 32,72 pesetas en 1913 a 69 en 1916, además se produjo un aumento del consumo por la peor calidad del mismo. El encarecimiento afectó también a otros elementos de la explotación; los carriles pasaron de costar 196 pesetas, 
Los documentos consultados dividen el personal en dos grandes grupos: agentes fijos o de las plantillas - nominales y numéricas-y agentes, que bajo distintas denominaciones permanecen fuera de las mismas. Los agentes de plantilla ejercen su actividad de manera permanente «sin más discontinuidad que la correspondiente á sus descansos, licencias o enfermedades, y disfrutan de todas las ventajas reconocidas por la compañía» ${ }^{29}$. Evaluar su cuantía aproximada no plantea mayores dificultades, pues, al margen de cuál sea la naturaleza del cómputo, sus activos aparecen siempre recogidos con claridad y se indican en los Presupuestos de forma muy pormenorizada.

Los agentes fuera de las plantillas «se reclutan para atender ciertas tareas», trabajan de modo intermitente y, «en rigor, no deberían disfrutar [de] ninguna ventaja». Pero el hecho real es, sin embargo, que se trata de un colectivo muy heterogéneo donde, como los propios directivos reconocen, hay demasiada confusión. Bajo una misma denominación - «temporero»- se esconden realidades muy diversas, según el servicio y la actividad de que se trate. Se les llama temporeros en Material y Tracción, auxiliares en Vía y Obras y suplementarios en Movimiento. La variedad que existe en las denominaciones que recibe esta clase de personal existe también en las formalidades que se les exigen para el ingreso como temporeros, suplementarios o auxiliares, «[...] la falta de reglamentación sobre este personal, que no es de plantilla, da lugar a que cada servicio tome sobre sí mismo disposiciones distintas [...] produciéndose diferencias siempre odiosas y que es de suma conveniencia evitar» ${ }^{30}$.

En las oficinas de los Servicios de Contabilidad, Intervención y Estadística, Almacén, Economato, Movimiento, Vía y Obras y Material y Tracción los auxiliares son trabajadores a prueba, quienes, antes de entrar, tienen que mostrar «suficiencia». «Al cabo del año, si su comportamiento, celo y demás condiciones personales les hace admisibles», pasan a ser «fijos de plantilla» con los ingresos sensiblemente mejorados ${ }^{31}$.

como promedio en 1913, a 550 pesetas en 1916, y lo propio sucedió con la clavazón de la vía, los tubos de humo, el cobre en placas y las llantas para las ruedas.

${ }^{29}$ Anticipos sin interés, economato, vivienda, gratificaciones, licencias anuales y descansos quincenales remunerados, socorros en casos de enfermedad, pensiones, billetes para agentes, etcétera.

${ }^{30}$ AHF: C/49/6.

${ }^{31}$ En algunas fuentes se denominan también «aspirantes». En 1909 la plantilla reconoce a 125 aspirantes dentro de una plantilla de administración compuesta por 489 auxiliares, 564 oficiales y 248 jefes de negociado. AHF: C/49/4. 
Provisional es igualmente la situación de los alumnos en prácticas y aspirantes a factores o factores al estudio del servicio de Movimiento. Son siempre hijos o parientes de empleados quienes tras examen de aptitud, y antes de integrarse definitivamente en la plantilla, deben realizar las correspondientes prácticas. No siempre figuran en las plantillas por no ser propiamente temporeros, sino que, como los mismos informes indican, se trata de «personal de estudio para ingresar de plantilla». Lo que no quiere decir que, a menudo, la situación de interinidad se prolongue en exceso por existir «sobrante» ${ }^{32}$. En todo caso, su número, como el de los auxiliares, fue siempre reducido, y la incidencia dentro de la oferta global del empleo ferroviario muy escasa.

Donde la temporalidad cobra su verdadera dimensión es en los servicios de Movimiento, Vía y Obras, y Material y Tracción, los cuales aglutinaban el 90 por 100 de los activos de la compañía. En Movimiento las «faenas de carga, descarga, removido y transbordo en las estaciones, cuya intensidad varía con las oscilaciones del tráfico, exige muchas veces el concurso de temporeros que también llegan a ser en parte semi-fijos» ${ }^{33}$. Estos trabajos son realizados tanto por los mozos suplementarios - disponen de expediente personal, pero no figuran en la plantilla - como por simples jornaleros. Ambos trabajan entre diez y catorce horas, se contratan únicamente en las estaciones de su residencia los días que son requeridos y cobran en consecuencia. Transcurrido más de un año, los mozos suplementarios - los jornaleros no- tienen derecho a billetes de servicio y a cartilla del economato si residen en Madrid, y de entre ellos se elige el que habrá de ser de plantilla. Su número fue siempre variable y su registro aleatorio ${ }^{34}$. Conviene no olvidar que MZA - y como ella es de suponer que todas las demás concesionarias- se mostró siempre muy cicatera a la hora de repetir contratos para evitar que dichos empleados se hicieran acreedores de sus prestaciones.

Análoga situación presentan los obreros auxiliares y los obreros especiales auxiliares del servicio de Vía y Obras ${ }^{35}$. Dentro de los primeros

${ }^{32} \mathrm{E}$ total de alumnos de la compañía ascendía, en noviembre de 1916, a 386; de ellos, 207 eran hijos de empleados y los 179 restantes tenían algún pariente en la compañía, AHF: C/49/4 y C/49/6.

${ }_{33}$ AHF: C/49/6.

${ }^{34}$ En 1911 comprendian 662 mozos de estación y 1.712 suplementarios, es decir, un total de 2.374 agentes. Una cifra que, con ligeras variaciones, se repite en $1913-2.187-$ y en $1914-2.250$ - En 1916, en cambio, se registra un descenso, situándose para ese año en 1.746 agentes. AHF: $\mathrm{C} / 188 / 56, \mathrm{C} / 115 / 14$ y $\mathrm{C} / 49 / 9$, y Relaciones Numéricas del personal, 1913.

35 Una excelente exposición de las difíciles condiciones de trabajo de los empleados de este Servicio en Matallana (1873). 
los había con carácter de fijos - solían cubrir carencias y realizar suplencias de la plantilla y cubrir plaza de la misma cuando se producían vacantesy con carácter de temporeros propiamente dichos; ambos se dedicaban a la conservación y vigilancia de la vía, podían disponer al año de servicio, de billetes y cartilla del economato y, después de dos años, acceder a la petición de «anticipos gratuitos». El segundo grupo lo integraba el personal suplementario que podía reforzar a las brigadas, pero su principal cometido era el trabajo extraordinario, ya fueran obras nuevas, renovación y reparación de las antiguas, montaje de máquinas, etc. Carecían de todo derecho dentro de la compañía y era muy difícil que alguno de ellos accediera a la plantilla. Las condiciones de trabajo eran, para unos y otros, muy duras ${ }^{36}$.

La posición de los temporeros de los depósitos y suplementarios del servicio de Material y Tracción es idéntica en derechos a la que disfrutaban sus homólogos de Movimiento y apenas difería de la de los auxiliares de Vía y Obras. La dilatada precariedad en la que se mantenía a estos trabajadores generó un creciente malestar entre ellos, así como un bajo rendimiento. En 1916 el ingeniero jefe de Material y Tracción expone al Director General la conveniencia de que la temporalidad no exceda de doce meses, «ya que ahora alcanza 19 , y que se reconozcan las ventajas oportunas a estos trabajadores ya que son muchos los que se lamentan, otros renuncian al ingreso al enterarse de las condiciones en las que ingresan, y no pocos dimiten al poco de ingresar para colocarse en otras industrias donde existe gran demanda de empleo» ${ }^{37}$. En ese mismo año, el Comité sindical en MZA de la Federación Nacional Ferroviaria solicitó a la Dirección que, además de integrar en la plantilla a todo agente que hubiera cumplido un año de servicio, acabara con las contratas. La respuesta del Consejo de Administración fue, tal como era de esperar, negativa, pues no estaba dispuesta la Compañía a reconocer como agentes de plantilla a trabajadores que no podían considerarse «empleados propiamente del ferrocarril», ni tampoco quería renunciar a los beneficios económicos que le reportaba dicho sistema ${ }^{38}$. Se trata de una reacción bastante comprensible del Consejo ante la rigidez del mercado laboral ferroviario que, con la excepción

${ }^{36}$ Este personal se reclutaba «entre los que se dedican a las faenas del campo y no siendo trabajo más fatigoso que aquél ni que requiera mayor atención, se tiene establecido que el trabajo de estos agentes sea, como el de aquéllos, de sol a sol, con descanso para las comidas, de una hora en inviemo y de tres horas en verano». AHF: C/188/56.

${ }^{37}$ AHF: C/3/8.

${ }^{38}$ AHF: C/185/23. 
de incentivos y horas extraordinarias, convertía la mayor parte de los gastos de personal en costes fijos.

De los tres flujos de contratación de personal: a) trabajadores de plantilla -nominal o numérica-; $b$ ) personal semifijo o con grandes posibilidades de integrarse en la plantilla, y $c$ ) personal temporero en el sentido más absoluto de la palabra, este último es el más difícil de evaluar, pues de su presencia quedan pocos vestigios, sobre todo antes de 1920. Puede encontrárseles, a veces, bajo el ambiguo epígrafe de «personal suplementario, temporero y de contrata», y se les asocia con las grandes obras, con el removido de mercancías, la carga de ténders, limpieza de máquinas, etc., si bien también se les puede ver en las estaciones y puertos realizando actividades importantes como la carga y descarga de carbón ${ }^{39}$.

Todo ello no tendría mayor interés para este trabajo si no fuera porque, como reconoce la propia Dirección, la frontera que separa a los trabajadores jornaleros semifijos del personal jornalero fijo, de un lado, y de los temporeros propiamente dichos, del otro, no estuvo en absoluto clara, pudiendo aparecer a menudo entremezclados, según el criterio particular que en ese momento guió al contable o de acuerdo con el interés que revistiera el expediente en cuestión. La descentralización del servicio de Contabilidad en 1909 pudo contribuir a la falta de precisión, ya que a la oficina central llegaría información muy desigual, dependiendo del celo y el criterio de los responsables de remitir las estadísticas de personal.

De los diversos expedientes donde se alude a la magnitud del empleo no estable se considerarán dos, referidos al difícil período que transcurre entre 1919 y $1930^{40}$. Coincidiendo con la implantación de la reducción de la jornada laboral la compañía incorpora, en algunos de los informes internos, el importe de los haberes abonados al personal suplementario y jornalero, así como el número medio de agentes al día para el conjunto del año (Tabla 2, columna 5). El recurso a este tipo de empleo aumenta con el devenir de los años, alcanzando su máximo en 1925 con 11.403 trabajadores. Como era de esperar, estos efectivos se contratan casi exclusivamente en los servicios de Vía y Obras, Movimiento, y Material y Tracción, y su vinculación con la actividad ferroviaria era meramente ocasional —establecimiento de doble vía, construcción de puentes y estaciones,

\footnotetext{
${ }^{39}$ AHF: $\mathrm{C} / 49 / 6$.

4) AHF: C/53/33 y C/53/34, y MZA (1933 y 1935).
} 
etc.-- Eso explicaría su elevado y fluctuante volumen ${ }^{41}$. En la Tabla 3 se reúnen datos seriados del personal no estable, diferenciando su naturaleza en los dos grupos principales: suplementarios y personal de contratas. Las cifras, según la fuente, se estiman a partir de las cantidades presupuestadas para «trabajos extraordinarios y complementarios» dentro de la explotación y teniendo en cuenta el precio medio de los jornales por trabajador. El hecho de que los datos sean una estimación revela el desinterés de la compañía por ejercer un control estadístico sobre estos trabajadores a los que toma como mano de obra barata en momentos de necesidad.

\section{TABLA 3}

Número de agentes semifijos y temporeros en toda la red de MZA, 1919-1930

\begin{tabular}{|c|c|c|c|c|}
\hline Años & $\begin{array}{c}\text { Suplementarios } \\
\text { y jomaleros }\end{array}$ & $\begin{array}{c}\text { Personal de las } \\
\text { contratas }\end{array}$ & Total & $\begin{array}{l}\text { Diferencias entre } \\
\text { Anuario-Presup. }\end{array}$ \\
\hline $1920 \ldots$. & 1.712 & $1.288^{*}$ & 3.000 & 1.603 \\
\hline $1922 \ldots \ldots$ & 2.150 & 1.380 & 3.530 & 2.898 \\
\hline 1924 & 1.182 & 2.625 & 3.807 & 3.427 \\
\hline 1925 & 3.200 & 1.000 & 4.200 & 3.615 \\
\hline 1926 & 3.167 & 1.602 & 4.469 & 1.870 \\
\hline 1928 & 2.445 & 1.838 & 3.283 & $\begin{array}{l}1.0 / 0 \\
1.977\end{array}$ \\
\hline 1929 & 2.970 & 1.875 & 4.845 & 1.310 \\
\hline 1930 & 2.607 & 1.893 & 4.500 & 2.519 \\
\hline
\end{tabular}

" Estimación propia ${ }^{42}$

Fuente: Resumen de los Presupuestos de la Red Antigua y la Red Catalana, 1919-1930 (libros 269-277).

El personal suplementario fue el más numeroso ${ }^{43}$. El de las contratas se especifica desde 1922 y se ocupa en el removido de mercancías, carga de ténderes, descarga de carbón, limpieza de máquinas, manipulación de

${ }^{41}$ Esta misma información puede aparecer en ocasiones compendiada en las Memorias presentadas por el Consejo de Administración a la Junta General de accionistas, con la siguiente nota: «La mitad (en otras ocasiones se habla de dos tercios) aproximadamente de estos haberes corresponden a agentes empleados en obras de primer establecimiento o realizados con cargo al fondo para obras de mejora y al de amortización del material.» Libros de Memorias (1920, p. 17; 1921, p. 21; 1922, p. 20, y 1923, p. 18).

作 incluidas en AHF: C/58/37, y los libros de los Resúmenes de los Presupuestos de ambas redes.

t3 Según los cálculos de la MZA, el total real de trabajadores, sin incluir minas y con- 
placas giratorias, removido y maniobra de talleres y depósitos y contratas de almacenes. A la luz de los resultados parece probable que el Anuario incluyera en los totales relativos a la MZA las cifras de alguno de los colectivos que conformaban el empleo no estable —la hipótesis más lógica apuntaría hacia los suplementarios.

Cuando se compara el volumen de empleo de MZA con el de Norte sorprende la gran diferencia existente a favor de la segunda, siendo así que el tendido de la red y el volumen de tráfico eran, sin embargo, similares. El hecho no ha pasado desapercibido para los historiadores, aunque no se ha dado ningún tipo de explicación convincente hasta la fecha. Podría pensarse —es lo más lógico- que MZA siguió una política de personal más racional que Norte. No estamos seguros de ello, especialmente porque el flujo de comunicación entre ellas sobre este problema fue grande. Aunque por el momento los datos no puedan ser contrastados, nos inclinamos a pensar, más que en los criterios de racionalidad, en que Norte regularizó antes un mayor porcentaje del empleo temporal. Esta hipótesis se apoya sobre la observación de que las múltiples políticas sociales en esta compañía se implantaron con una cronología anterior que en $\mathrm{MZA}^{44}$.

En suma, ahora estamos en disposición de afirmar que la estadística que se deduce del Anuario -al menos en lo que a las empresas líderes se refiere- se aproxima bastante a la realidad. Enrique de la Torre, por su condición de trabajador en Norte, debía de conocer bien los complejos mecanismos del empleo en el mundo ferroviario. Y, aunque no consta explícitamente en su colección, debió de haber solicitado a las concesionarias que remitieran el total de trabajadores contratados, con independencia de su rango o posible temporalidad ${ }^{45}$. Se puede afirmar que el Anuario de Ferrocarriles Españoles posee al menos dos ventajas: 1. ${ }^{\mathrm{a}}$, reúne en una misma fuente la información del empleo para todo el sector, desagregando los datos por compañías, y $2{ }^{a}$, las cifras publicadas se ajustan a la oferta real del sector ferroviario español. Conviene, sin embargo, no perder de vista que los datos elaborados son una estimación más que aceptable, pero estimación al fin, pues la documentación, como se ha señalado,

tratas, ascendía a 25.945 en 1919; de ellos 23.398 eran agentes de plantilla y 1.828 suplementarios, Resumen de los Presupuestos de la Red Antigua y Red Catalana (libro 269, folio 68).

44 Martín-Gamero (1891, p. 151) y Juez Gonzalo (1992, pp. 647-648).

45 De él debió de tomar Ceballos Teresi (1932, VII, pp. 374-375) la información que sirvió de base para la construcción de su interesante estadística que abarca el periodo 1901-1930. 
presenta deficiencias. Recuérdese que algunas concesionarias retrasaron en demasía el envío de sus datos, otras lo hicieron de manera discontinua y las hubo que remitieron injustificadamente idénticos guarismos. No obstante, desde el segundo año de su publicación el Anuario recoge los resultados de las tres firmas más importantes (Norte, MZA con la Red Catalana y Andaluces), cuyos efectivos representaron siempre más del 72 por 100 del total del mercado de trabajo del sector, y más del 82 por 100 , si sólo se tienen en cuenta los activos de vía ancha.

Las divergencias observadas entre las cifras que proporciona el Anuario y las que aparecen en los recuentos empresariales se deben a la inclusión o no del personal temporero, un colectivo heterogéneo y de cambiante cómputo en la cronología de análisis. Su enumeración y cálculo supusieron uno de los caballos de batalla de las grandes compañías ${ }^{46}$. Resulta muy ilustrativo señalar que esta situación no se normalizó hasta la década de los cincuenta del siglo xx. En 1942 la plantilla de Renfe era de 110.000 personas, un año después la cifra se elevó a 122.694, llegando a su máximo histórico en 1954 con un total de 137.622 agentes. Este significativo crecimiento se debió a la regularizacion y definitiva incorporación en la plantilla del que hasta entonces había sido personal eventual de las antiguas compañías, ahora nacionalizadas ${ }^{47}$.

\section{LA EVOLUCIÓN DEL EMPLEO EN EL SECTOR FERROVIARIO ESPAÑOL, 1893-1935}

Después de justificar por qué los datos que suministra el Anuario son, por el momento, la mejor y única fuente para conocer de manera apro-

${ }^{4}$ La peculiar y ambigua contabilidad de los trabajadores temporales se refleja en la resistencia premeditada de las compañías a reconocerlo como personal ferroviario ya desde los años de formación de las concesionarias. Con motivo de la presentación del presupuesto económico relativo al año 1860, la Comisión de Cuentas de la MZA advierte sobre el aumento del mismo a consecuencia del aumento de plantilla y añade: «[...] ha sido con el fin de disminuir el número de suplementarios, habiéndose recomendado al Director que éstos sean reducidos solamente a los más indispensables», ACA, 30 de diciembre de 1859. El Proyecto de Estatuto del personal ferroviario (1933) indica que la denominación de personal eventual corresponde a «aquellos agentes que prestan un servicio puramente ocasional, y que pueden ser reclutados o admitidos por los jefes de servicio cuando precisen de ellos» (articulo 21); asimismo ordena a las distintas dependencias que lleven «un libro registro (lo que quiere decir que aún no se hacía) donde consten el nombre, cargo y tiempo servido por estos agentes de ferrocarriles». El hecho era importante porque, después del año de servicio ininterrumpido, las concesionarias deberían convertir este personal en fijo, disfrutando, desde ese momento, «de todos los beneficios concedidos a este personal», Boletín de la Asociación General de Transportes por via férrea (1933).

47 Muñoz (1995, pp. 163-164). 
ximada la evolución del empleo en el sector ferroviario español, se especifican los criterios seguidos en la elaboración de las series estadísticas.

Se han construido para cada tipo de vía dos series, en las primeras (columna B de las Tablas 1 y 2 del Apéndice, pp. 673-6) se reproducen los datos originales, tal como fueron apareciendo en el Anuario, mientras que en las segundas (columna $C$ de las Tablas 1 y 2) los datos han sido ligeramente corregidos. Se ha buscado neutralizar el retraso con el que algunas concesionarias comenzaron a remitir los datos, teniendo en cuenta el año en el que la línea empieza a funcionar con regularidad, y se ha retrotraído a ese momento la primera cifra disponible ${ }^{48}$. Por eso existe al principio esa gran diferencia entre ambas series. Se trata de una operación laboriosa y quizá no muy ortodoxa, pero necesaria y operativa para proceder a la estimación del empleo en el sector. En los casos en los que una compañía suspende de manera transitoria los envíos, remite alguno claramente erróneo, o bien se detecta una errata tipográfica, si la línea opera con normalidad y la interrupción no sobrepasa los dos años se mantiene el último guarismo. Excepto en los casos de Norte y MZA, este mismo procedimiento se siguió en 1929 y 1932, años para los que el Anuario no ofrece información ${ }^{49}$. Las discrepancias con las series sin modificar son relativamente pequeñas, pero no desdeñables si se quiere obtener una correcta interpretación de las mismas.

Finalmente, el total del empleo se obtiene por agregación de las series parciales - vía ancha y vía estrecha-. En el transcurso de los cuarenta y dos años que recorren las series (Gráfico 1) el número total de operarios se multiplicó casi por tres, pasando de 41.265 agentes como promedio en el quinquenio 1893-1897 a 122.504 en el de 1931-1935. Semejante

${ }^{48}$ Las notas que acompañan a las fechas de las tablas señalan los inicios y la secuencia de los envíos.

49 La serje de empleados de vía ancha ha mejorado con las correcciones realizadas. En el caso de Norte y para el período 1913-1935 se han reemplazado los datos del Anuario por los de Marquina. Como se indicó en su momento, la información proporcionada por el antiguo director parece más plausible que la del Anuario, al menos las cifras son más homogéneas, no hay repeticiones y tampoco se observan escalones difíciles de justificar. Por otro lado, el desplome que en el Anuario experimenta el nivel de empleo de los ferrocarriles catalanes desde 1933 se debe a que, a partir de 1932, año no recogido por el Anuario, los efectivos del servicio de Vía y Obras aparecen contabilizados dentro de la red general; se ha depurado la serie con información proveniente de los Presupuestos. También con información de los mismos se rellenaron los huecos de 1929 y 1932 para toda la red de MZA. Sería deseable excluir de las relaciones de personal a los mineros, pues no son propiamente trabajadores del ferrocarril, pero con las fuentes disponibles no es posible; no obstante, su número aproximado puede cifrarse entre 2.500 y 3.000 , volumen que no debió oscilar demasiado a lo largo del período. 


\section{GRÁFICO 1}

Evolución del empleo ferroviario según el tipo de vía, 1893-1935

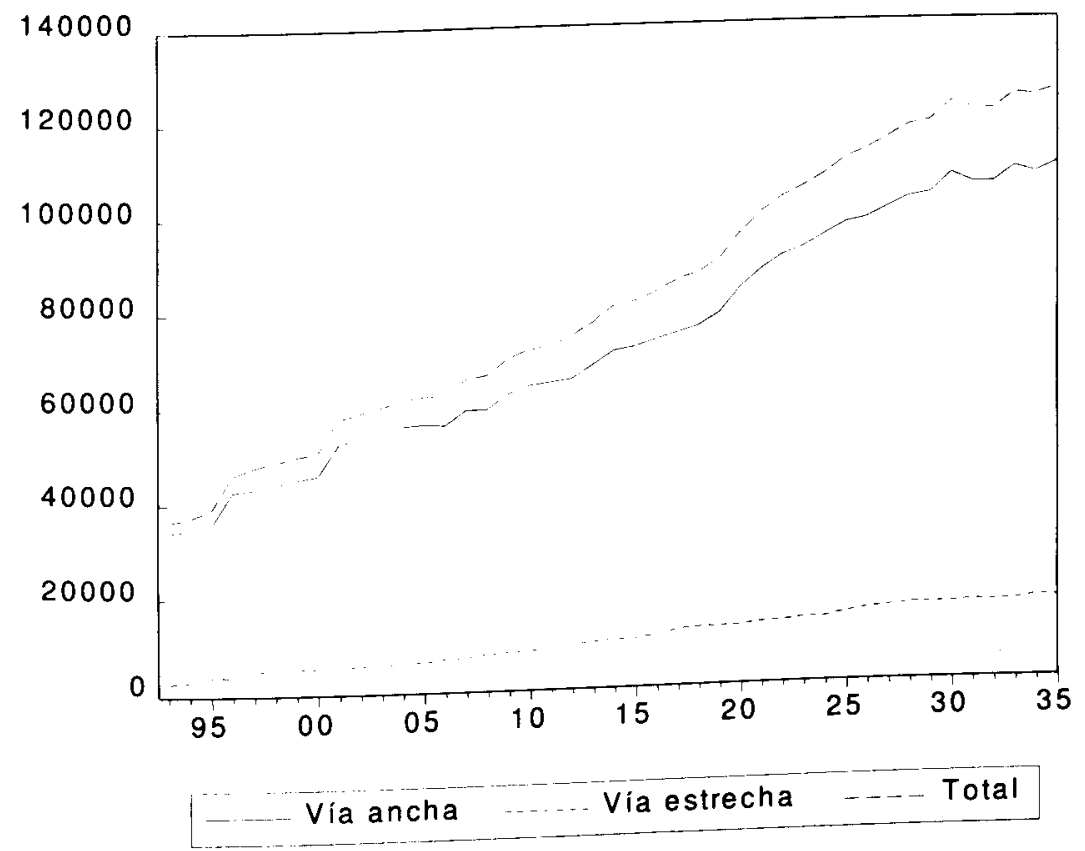

dinamismo a la hora de crear empleo tiene pocas semejanzas en los otros sectores de la economía, sin contar la agricultura, que como es bien sabido, está desde hace tiempo cediendo parte de sus efectivos ${ }^{50}$. Entre 1901 y 1930 el número de trabajadores del sector minero, por ejemplo, se incrementó en un 55 por 100 -de 109.549 activos se pasó a 169.707-, mientras que el ferroviario en igual período lo hizo en un 220,5 por 100 , con el añadido de que se trataba de un empleo menos irregular y precario ${ }^{51}$. Son varias las causas que explican este espectacular incremento. La serie arranca cuando el país está saliendo lentamente de la crisis agraria y dejan ya de percibirse sus efectos sobre los demás sectores de la economía. El resultado es un crecimiento de la demanda de servicios ferroviarios,

50 Erdozáin y Mikelarena (1999).

"La información de los trabajadores de las minas procede de Ceballos Teresi (1932, VII, p. 337). 
si bien no en la proporción esperada por las compañías, tal como dejan bien claro las cuentas de resultados ${ }^{52}$. La guerra hispano-norteamericana supuso una breve inflexión, muy pronto superada por el gran auge que siguió y al que no es ajena, desde luego, la política monetaria y financiera enérgica y ortodoxa de Raimundo Fernández Villaverde ${ }^{53}$. La tendencia alcista de la demanda de transporte se mantiene, acelerándose, tras un breve paréntesis - 1913 y 1914 - durante la guerra europea ${ }^{54}$. En efecto, tras la fugaz contracción (Anuario, 1914, p. 2), la producción reanuda su proceso ascendente, los negocios de las empresas se animan, crecen las exportaciones y el tráfico acude con más intensidad al ferrocarril. Esta respuesta positiva de la oferta de transporte fue posible, en el caso de los ferrocarriles de vía ancha, gracias no tanto a la ampliación de la red ${ }^{55}$, como a la renovación del material móvil, la mejora de la infraestructura ${ }^{56}$, un uso más intensivo y racional de todos los recursos disponibles, y, sobre todo, al empleo de un número mayor de agentes por kilómetro de red y por unidad de tráfico ${ }^{57}$. Los kilómetros recorridos por los trenes de

52 Comín, Martín Aceña, Muñoz y Vidal Olivares (1998, pp. 203-238).

${ }^{53}$ Carreras (1990, pp. 155-162).

${ }^{54}$ Momentos antes de que la Gran Guerra dejara sentir de forma clara sus efectos sobre los gastos de explotación, aparece en España Económica y Financiera - 13 de marzo de 1915 - un excelente artículo - el cuarto de una serie dedicada a la politica ferroviariadonde se explica, con gran lucidez, la situación en el momento de la mayor parte de las concesionarias. La pérdida del imperio colonial coincidió - explica - con un resurgir de la actividad nacional. Esa actividad impulsó el tráfico de viajeros y mercancías, lo que produjo en las compañías una crisis de crecimiento, poniendo de manifiesto la inadecuación de la red para este movimiento en alza del tráfico. Es necesario -añadía- doblar las vías, construir amplias estaciones de mercancías, adquirir material, etc. La Primera Guerra Mundial no hará sino ahondar en el surco abierto.

35 Entre 1896 y 1935 se construyeron líneas marginales, Cordero y Méndez (1978, I, pp. 258-260); entre ambas fechas, lejos de completarse la red arborescente, sólo se añadieron 171 kilómetros, Gómez Mendoza (1989a, p. 54). El inspector del cuerpo de Ingenieros de Caminos, Canales y Puertos, Borés Romero (1918), realiza un comentario muy crítico sobre la escasa actividad constructora de carreteras y ferrocarriles, culpando a las concesionarias, pero sobre todo al Estado.

36 Maristany (1905-1908), Cayón, González y Muñoz (1998).

${ }^{57}$ Según Marquina (1940, p. 431, gráfico 73 y cuadro 39), en Norte «el número de agentes por kilómetros-tren pasa de 1,02 en 1906 a 1,37 en 1935, con un máximo de 1,54 en el año 1918; y por millón de unidades de tráfico, pasa de 9,65 en 1906 a 11,47 en 1935, con un máximo en el 34 de $11,51 »$. Las plantillas numéricas de MZA vieron incrementarse sus efectivos en los servicios de Movimiento, Vía y Obras, y Material y Tracción en un en 13,4 por 100 «debido al mayor tráfico». AHF: C/86/36. Entre 1913 y 1929 el personal fijo de toda la red de MZA aumentó en un 45 por 100 , debiéndose, según la propia compañia, al «incremento del tráfico y a la implantación de la jornada de ocho horas», MZA (1934, p. 17). 
Norte y MZA aumentaron en un 50 por 100 durante los tres primeros quinquenios del siglo $\mathrm{XX}^{58}$. El aumento del tráfico no explica por sí sólo el espectacular crecimiento de los activos. El incremento del empleo se debe también, en el caso de los ferrocarriles económicos, a la ampliación de la red que acaba configurándose de forma definitiva en estos años, pasándose de 1.968 kilómetros en 1893 a 4.550 en 1935 (Tabla 2, columna A del Apéndice, p. 675). El ritmo de crecimiento de las dos series es muy diferente: muy vivo y sostenido en la de los ferrocarriles de vía estrecha; más pausado en los de vía normal, ya que para éstos la red se había consolidado muchos años atrás.

La tercera y última de las razones que explican el incremento del empleo en el sector tiene que ver con las normativas estatales sobre retiro obrero, descanso semanal y, sobre todo, con la implantación de la jornada laboral, de ocho horas, medidas que habían venido ya precedidas por no pocas concesiones efectuadas por algunas compañías ${ }^{59}$. Esta última fue establecida en $1919-\mathrm{RD}$ de 15 de marzo- para los trabajadores industriales, pero no resultaba sencilla su aplicación en el sector ferroviario debido, sin duda, a las especiales características de muchos de los servicios, y al temor de las compañías a que se dispararan aún más los costes de explotación, lo que era denunciado una y otra vez por las concesionarias ${ }^{60}$. Según Marquina (1940, p. 431) Norte comenzó a notar los primeros efectos del decreto en 1921 y lo propio sucedió también en MZA, como advierte Maristany, coincidiendo con los primeros síntomas de malestar por parte de los ferroviarios debido al retraso en la aplicación del mismo ${ }^{61}$. Volviendo al Gráfico 1

${ }^{\varsigma x}$ Cordero y Menéndez (1978, p. 318).

54 Entre 1913 y 1914 MZA se vio obligada a incrementar en toda su red el personal Extensión a toda la plantilla numérica de los «descansos periódicos» - Orden de Dirección núm. 196, 21 de diciembre de 1912-que antes sólo disfrutaban los oficinistas y el personal de trenes, AHF: MZA, C/86/36 y C/115/14.

(11) Según André (1919, p. 373), el personal obrero era «la mampara y el coco, del cual indirectamente se valian la compañías para intimidar al Gobierno y a la opinión, a fin de lograr el 50 por 100 en la elevación de sus tarifas». Meses después de promulgarse la normativa se formó un comité paritario de ferrocarriles al objeto aclarar el camino y «proponer todo lo necesario para su cumplimiento». Pero las concesionarias, temiendo con razón la incidencia que ello habría de tener en unos costes salariales que ya consideraban excesivos, se resistieron a su aplicación efectiva en todo el personal. Comín, Martín Aceña Vidal Olivares y Muñoz (1998, p. 334). Sobre la implantación de la jornada de ocho horas en cl sector ferroviario ver también Juez Gonzalo (1999) y Soto Carmona (1989).

"IHF: C/58/37; MZA (1934, p. 17); según España Económica y Financiera -8 de (a) ferroviarios ya comenzaban a sentirse impacientes por la tardanza en implantarse la jornada de ocho horas. 
(p. 659), se comprueba que las observaciones de Marquina y Maristany son correctas. La normativa no se cumplió con la celeridad prevista y por ello tenían razón los sindicatos al denunciar que más de la mitad de los trabajadores del sector no tenían aún una jornada efectiva de ocho horas. Algunos agentes habrían de esperar hasta el Decreto de 1 de julio de 1931, los que ejercían la vigilancia de la vía que antes habian sido excluidos ${ }^{62}$, y hasta la Orden del Ministerio de Trabajo de 21 de julio de 1932 todo el personal de las estaciones ${ }^{63}$.

Tradicionalmente, el peso de las grandes compañías ferroviarias ha eclipsado la atención sobre las empresas homólogas de menor importancia, pero éstas coexisten con aquéllas en la formación del sector. En las características de este mercado de trabajo se pueden apreciar algunas situaciones contrapuestas según el tipo de vía.

Las concesionarias de vía ancha absorbieron, entre 1893 y 1935 , el 90 por 100 del empleo total. En la estimación se ha recogido información para más de 40 compañías con desigual incidencia en la actividad económica. Desde el punto de vista de la explotación, sólo 18 mantuvieron una actividad continua y autónoma en la cronología de análisis, el resto se vio inmerso en procesos de integración de empresas. Desde el punto de vista de la contratación, las concesionarias se pueden clasificar en tres grupos. En primer lugar hay que señalar el protagonismo indiscutible de Norte y MZA como líderes en la contratación de activos, no sólo dentro del sector sino en el conjunto de la economía española, lo que ha sido puesto de manifiesto por Carreras y Tafunell (1996). Existiría un segundo

${ }_{62}$ Marquina (1940, p. 436). Cierran el círculo de medidas que directa e indirectamente afectan a la contratación de empleados y llenan de inquietud a las empresas: Orden Ministerial de 8 de abril imponiendo el descanso quincenal retribuido; Orden del Ministerio de Trabajo de 27 de mayo de 1932 implantando la jornada de ocho horas en las guarderías de los pasos a nivel e imponiendo la obligación de afiliar los obreros eventuales al régimen ordinario de retiro obrero; Orden 16 de junio de 1932 limitando las horas extraordinarias al personal de máquinas y fogoneros; $y$, finalmente, Orden de 21 de julio de 1932 implantando la jornada de ocho horas en los servicios de estaciones, Marquina (1940, pp. 437-438). En un escrito dirigido a la opinión pública por la Agrupación de Accionistas y Obligacionistas de los Ferrocarriles en los primeros meses de 1932, señala como una de las causas más graves de la crisis del sector «la elevación de jornadas decretada en marzo de 1931 [...] y el aumento de las guardabarreras y cómputo de horas extraordinarias». De ahí que, entre otros remedios, proponga la «suspensión de toda medida de Gobierno que pueda producir encarecimiento en los costos de explotación», España Económica y Financiera, 21 de mayo de 1932.

(3) Un resumen de lo que supusieron estas medidas para Norte y MZA puede leerse en La dificil situación financicra de los grandes ferrocarriles españoles. Causas y posibles soluciones (1934, p. 15); más información en Imedio (1934). 
grupo de tamaño intermedio, entre los 4.000 y 10.000 empleados, donde deben situarse la Compañía de los Ferrocarriles Andaluces, $\operatorname{TBF}^{64}$ y la Compañía de Madrid, Cáceres y Portugal — considerando su continuación en Ferrocarriles del Oeste de España-. Y, finalmente, habría un conjunto numeroso de pequeñas empresas cuyo volumen de contratación no superó los 1.000 individuos. Entre ellas señalaremos, en el límite superior, a la Compañía de los Ferrocarriles de Zafra a Huelva y también al Central de Aragón, y en el inferior, la compañía de Ferrocarriles de Mollet a Caldas de Montbuy, cuyo personal se mantuvo en torno a 44 trabajadores. En definitiva, se puede constatar una diversidad similar a la de un único mosaico construido con piezas de tamaño muy desigual.

Las concesionarias de vía estrecha ofrecen un panorama más homogéneo; de los 60 casos que han sido incluidos en la estimación sólo 22 desarrollaron su explotación con continuidad entre finales del siglo XIX y 1935. El empleo en estas compañías tuvo un carácter más modesto que en las de vía ancha. Las compañías más grandes contrataron entre 600 y 1.000 trabajadores - Ferrocarril de Langreo, de la Robla a Valmaseda, de Santander a Bilbao, y desde 1903, los Ferrocarriles Vascongados-. En un estadio intermedio contaríamos con empresas cuyo nivel de empleo osciló entre 100 y 500 trabajadores, tal sería el caso de las líneas de Alcoy, Cantábrico, Económicos de Asturias, Olot, Grao a Valencia, Tajuña, Peñarroya, Flassá y Onda al Grao y a Castellón. Y finalmente, se contarían aquellas cuya plantilla fue siempre inferior a 100 trabajadores: Silla-Cullera, Luchana, Cortés-Borja, San Feliú, Cariñena, Bilbao-Lezana, Buitrón.

Un requisito obligado antes de culminar el análisis es someter a comparación los resultados obtenidos con la estadística censal. En los censos de población del siglo XIX el personal ferroviario aparece diluido dentro de la rúbrica «empleados particulares y de ferrocarriles», sin que sea posible determinar qué proporción de aquélla correspondía a éstos. Únicamente en el de 1860 existe, dentro de las 39 rúbricas de clasificación, una denominada «empleados de ferro-carriles». El número total de individuos registrado asciende a 5.066, de los cuales una tercera parte se concentraba en Madrid, ciudad donde se ubicaban las estaciones terminales de Norte -Príncipe Pío- y MZA - Atocha-. El dato resulta exiguo, especialmente en el contexto en que se publica: ¿cómo contabilizó el censo a los obreros

${ }^{64}$ La integración en la MZA de la Compañía de los Ferrocarriles de Tarragona a Barcelona y Francia se realizó siguiendo el criterio de las ferroviarias americanas de respetar en la fusión la organización y autonomía de la compañía integrada, alcanzando, según Maristany, un excelente resultado. Maristany (1905, pp. 131-132). 
que se emplearon en la construcción de las principales líneas entre 1855 y 1865? Las Memorias de Obras Públicas señalan una ocupación en torno a 40.000 jornaleros para ese mismo año ${ }^{65}$. Ciertamente, el concepto «empleados del ferrocarril» está considerando sólo al personal de las plantillas, lo que confirma la tesis de que los censos del siglo XIX no siguieron en su elaboración criterios de actividad económica.

La clasificación de los activos mejora aparentemente en los censos del siglo $\mathrm{xx}$; los datos aparecen desagregados según las distintas modalidades del transporte. Sin embargo, las cifras asignadas al empleo por ferrocarriles resultan sospechosamente bajas en relación a nuestra estimación ${ }^{66}$. Los censos del primer tercio del siglo xx ofrecen una deficiente clasificación de los activos ferroviarios, incurriendo en un claro y significativo subregistro ${ }^{67}$. Para 1900 y 1910 contabilizaron, aproximadamente, un tercio del empleo total -36 y 33 por 100 , respectivamente-, mientras que en 1930 la estadística censal habría registrado a un 60 por 100 de los trabajadores. La explicación más plausible al respecto es que los datos censales podrían estar aludiendo exclusivamente a los «empleados», es decir, a los ferroviarios considerados como tales por las propias compañías. Es necesario recordar que la proporción de la plantilla sobre el empleo total en Norte osciló en el período que se extiende de 1900 a 1930 entre el 33 y el 36 por 100 - Tabla 1, columna 5-. Para MZA los datos son similares. En la relación de personal del años 1913 la propia compañía especifica el volumen de la plantilla sobre el empleo total, y el resultado se sitúa

69 Las cifras registradas en las Memorias de Obras Públicas son bien indicativas: 32.903 obreros en 1858; 38.755 en 1859; 37.677 en 1860, y 51.908 en 1861, Cordero y Menéndez (1978, pp. 1, 221-222).

66 Evolución de la población española ocupada en el sector transportes (1900-1930)

\begin{tabular}{|c|c|c|c|}
\hline & \multicolumn{3}{|c|}{ Datos censales } \\
\hline Modalidad & 1900 & 1910 & 1930 \\
\hline \multirow[t]{2}{*}{ 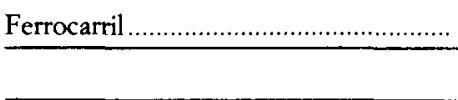 } & 18.290 & 23.640 & 74.624 \\
\hline & \multicolumn{3}{|c|}{ Estimación del empleo ferroviario } \\
\hline 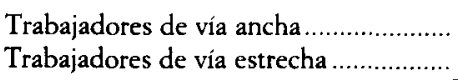 & $\begin{array}{r}45.850 \\
4.933\end{array}$ & $\begin{array}{r}63.900 \\
7.587\end{array}$ & $\begin{array}{r}106.602 \\
15.343\end{array}$ \\
\hline Trabajadores de los ferrocarriles ............ & 50.783 & 71.487 & 121.945 \\
\hline
\end{tabular}

Fuentes: Censos de la Población de España (1900, 1910 y 1930) y Anuario de los Ferrocarriles.

${ }^{67}$ No se incluyen los datos del censo de 1920 porque, como se sabe, los criterios de elaboración del mismo supusieron un ruptura tanto con el anterior como con los posteriores; en ese año las cifras aparecen agregadas bajo la rúbrica "transportes". 


\section{GRÁFICO 2}

Evolución del empleo en los ferrocarriles de vía ancha, 1893-1995. Trabajadores

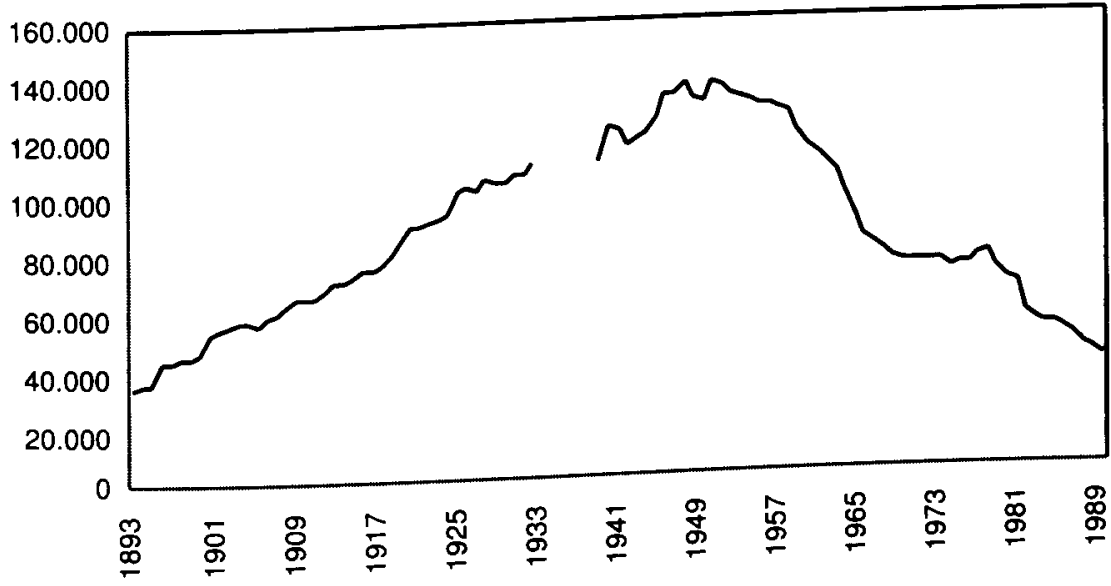

en el 31 por $100^{68}$. El aumento de los efectivos en el censo de 1930 podría estar respondiendo a una mejor aplicación de los criterios de elaboración de la estadística, pero con todo las modificaciones no resolvieron los problemas en la adecuada clasificación de la población trabajadora ${ }^{69}$.

Finalmente, y como se indicara al principio, la serie de empleo de vía ancha se ha enlazado con la publicada por Muñoz para el período Renfe. La evolución del empleo en los ferrocarriles de vía ancha entre 1893 y 1995 presenta un perfil de colina (Gráfico 2). El constante crecimiento de los activos ferroviarios, iniciado a mediados del siglo XXX con el nacimiento de las primeras compañías, alcanza su cumbre cien años después. En 1954 Renfe registra el máximo histórico en la contratación con 137.622 agentes, a la que sucederá en los siguientes cuarenta años una vertiginosa pérdida de efectivos. En números absolutos el empleo des. cendió en 100.000 individuos, lo que significa una caída del 260 por 100 . Curiosamente, el volumen de trabajadores presenta valores prácticamente iguales en los extremos de la observación. En 1895 la estimación resulta en 35.470 trabajadores, y un siglo más tarde -en 1995- se tienen 38.212 empleados.

${ }^{68}$ A similar conclusión liega Andrews (2000, pp. 54-70) para el área de Kent.

69 Relaciones Numéricas de personal..., 1913. 


\section{CONCLUSIONES}

La aproximación al empleo desde una fuente cuasi empresarial, como puede ser considerado el Anuario de los Ferrocarriles, resulta más ajustada y precisa que la que se deduce de las fuentes convencionales. En el caso del sector ferroviario español se puede demostrar la imprecisa clasificación de la estadística censal. Gracias a la información que proporciona el Anuario y tras la contrastación de sus datos, estamos en condiciones de asegurar que los censos del primer tercio del siglo xx cercenan el total de individuos efectivamente ocupados en los ferrocarriles, probablemente porque la lógica de la clasificación estuviera respondiendo a criterios no estrictamente económicos. No es descabellado pensar que los datos consignados en los censos se refieran sólo a los empleados nominales contratados por las compañías.

Los resultados obtenidos ponen de manifiesto el dinamismo económico del sector ferroviario español. La evolución del empleo se triplicó entre finales del siglo XIX y el primer tercio del siglo $\mathrm{xx}$; tan espectacular crecimiento no guarda semejanza con el resto de los sectores de la economía nacional. Son varias las razones que explican este fenómeno: el aumento del tráfico ferroviario, la expansión de la red de los ferrocarriles de vía estrecha y los cambios en la legislación del trabajo, especialmente la incidencia en la implantación de la jornada de ocho horas.

La literatura existente, como no podía ser de otro modo, ha destacado el importante papel de las grandes compañías como generadoras de empleo. Sin embargo, desde el punto de vista de los mercados de trabajo, conviene no olvidar que la explotación de dichas empresas coexistió con otras muchas, infinitamente más humildes en todos los sentidos. Incluso dentro de esas grandes compañías ferroviarias el mercado de trabajo interno fue sumamente heterogéneo. La clasificación entre personal fijo, semifijo - suplementarios, aspirantes o personal a estudio- y temporero propiamente dicho pone de manifiesto la existencia de mercados de trabajo interno fuertemente segmentados. Esta realidad creó a los propios gestores de las empresas innumerables problemas. A medida que aumentaba el tráfico, aquéllas se vieron obligadas a incrementar el empleo y lo hicieron con trabajadores a los que consideraban estacionales. Ocurrió, sin embargo, que el ritmo de la explotación hizo que muchos de estos «temporeros» resultaran imprescindibles, aunque las compañías se resistieron cuanto pudieron a hacerlos fijos esquivando el aumento de sus costes laborales. Obviamente esta es la razón principal que explica el subregistro de tra- 
bajadores en las estadísticas oficiales de las compañías analizadas — Norte y MZA.

La resistencia de las grandes compañías -y es de suponer que, por las mismas razones, también de las pequeñas-a regular la situación de sus respectivos temporeros no fue casual. El conjunto de las ventajas de las que disfrutaban los empleados de las plantillas era amplio (economato, billetes, licencias, pensiones, etc). Aumentar su número suponía multiplicar los costes fijos de personal y eso lo sabían muy bien los directivos que, desde la Gran Guerra, se vieron obligados a capear un temporal que amenazaba desde frentes muy diversos. Un tema muy vidrioso es el del personal de contratas y subcontratas. De él no se ha ocupado nadie hasta el momento. No sabemos cuánto empleo ocupó ni cuáles fueron sus condiciones de trabajo. La inestabilidad y el bajo nivel salarial se le presupone; como en los demás sectores de la actividad económica, se cumplió la máxima de que cuanto más bajo era el nivel de ocupación subcontratado más alto fue el número de trabajadores jóvenes y menores sus salarios.

La culminación de este trabajo emplaza a los investigadores a responder a un conjunto de preguntas sobre los distintos modelos de gestión de personal seguidos por las grandes empresas ferroviarias, así como a determinar su organización interna y a establecer las características principales de las relaciones laborales, dentro de las que han sido consideradas pioneras en la aplicación de la organización científica del trabajo. De algunos de estos asuntos nos estamos ocupando mediante el estudio de la compañía de Madrid a Zaragoza y a Alicante, entre 1857 y 1936.

\section{DOCUMENTACIÓN CONSULTADA EN EL ARCHIVO HISTÓRICO FERROVIARIO}

1. Actas del Consejo de Administración de MZA, 1857-1935.

\section{Cajas y expedientes:}

C/3/8: Proyectos y circulares de la Dirección sobre mejoras al personal.

$\mathrm{C} / 3 / 27$ : Relaciones de los datos de las compañías Norte y MZA sobre ingresos, gastos, carbón y personal, y su posible incidencia en el aumento de las tarifas. Remitidos por Maristany a Boix.

$\mathrm{C} / 49 / 4$ : Resumen de las actuales plantillas de aspirantes, auxiliares, oficiales y jefes de negociado.

C/49/6: Informe del subdirector Coderch - 2 de febrero de 1914- sobre el personal que presta servicio con carácter eventual o temporal. 
C/49/8: Estudio correspondiente a 1916 sobre diversas soluciones para mejorar al personal. Datos sobre agentes en 1916.

C/50/11: Datos que anualmente deben facilitar los servicios de la Dirección General sobre ventajas que disfruta el personal.

C/50/13: Peticiones de personal de talleres y almacenes para que se les conceda jornal diario.

C/50/15: Expediente sobre las bases para la organización del trabajo ferroviario a propuesta de la Dirección General de Obras Públicas del Ministerio de Fomento.

C/50/16: Estatutos de Personal correspondientes a varias compañias.

C/50/17: Instrucción General Núm. 2 de Norte.

$\mathrm{C} / 53 / 33$ : Ventajas diversas de que disfruta el personal de los diferentes servicios, 1915-1922.

C/54/34: Ventajas diversas de que disfruta el personal de los diferentes servicios, 1923-1930.

C/55/45: Ventajas diversas de que disfruta el personal de los diferentes servicios, 1931 y 1932.

C/55/47: Nota sobre reclamaciones en relación con el descanso semanal en los ferrocarriles.

C/58/35: Informes realizados para el Consejo de Ministros y Ministro de Fomento sobre los datos que justifican la elevación de tarifas. Diciembre de 1919.

C/58/36: Estudios sobre las mejoras y distribución del aumento de las tarifas y la aplicación de la jornada de trabajo de ocho horas. Octubre de 1919.

$\mathrm{C} / 58 / 37$ : Estudios sobre los diferentes proyectos de decretos de aumento de tarifas y su repercusión en la mejora de las retribuciones al personal.

C/58/41: Datos enviados por Norte [a la conferencia de 11 de mayo de 1920] sobre el importe de las mejoras que se pueden conceder al personal. Marzo de 1920 .

C/59/46: Discusión sobre el proyecto de ley de aumento del 35 por 100 de las tarifas en el Senado.

C/86/36: Ventajas otorgadas por la Compañia de MZA a su personal en 1913.

C/98/218: Expedientes diversos (causas de la crisis, justificación de la elevación de las tarifas y sus consecuencias). 1917 y 1918.

C/113/257: Nota sobre los gastos de explotación. 16 de diciembre de 1923.

$\mathrm{C} / 113 / 258$ : Contestación al informe de la Comisión sobre la intervención de la contabilidad de Norte el 13 de diciembre de 1923.

$\mathrm{C} / 115 / 14$ : Rendimiento medio del personal de las estaciones.

C/146/25: Documento firmado en nombre de las compañías de los ferrocarriles el 19 de noviembre 1919 por Luis Orlando, Pablo Rózpide y Rafael Coderch y dirigido al Excmo. Sr. Presidente del Instituto de Reformas Sociales.

C/185/23: Peticiones que formula el sindicato de MZA de la Federación Nacional de Ferrocarriles Españoles como consecuencia del Congreso celebrado en septiembre de 1916 y Acuerdo tomado por el Consejo de Administración en sesión 26 de enero de 1917.

C/188/52: Relación de agentes en los servicios de Vía y Obras y Material y Tracción. Expedientes de Personal de Norte, legajo 118 


\section{Libros de Presupuestos:}

Libros de Presupuestos de la Red Antigua, L. 45-195.

Libros de Presupuestos de la Red Catalana, L. 196-257.

Libros Resumen de los Presupuestos de la Red Antigua y Red Catalana, L. 269-277.

\section{Relaciones de personal:}

Relaciones numéricas del personal de plantilla y jornalero de las compañías Norte y MZA, 1913 (S. L.: S. N.).

Ventajas diversas de que disfruta el personal del ferrocarril de Madrid a Zaragoza y Alicante (1933 y 1935).

\section{PUBLICACIONES PERIÓDICAS}

Anuario de Ferrocarriles Españoles.

Economía Española.

España Económica y Financiera.

La Industria Nacional.

La Unión Ferroviaria.

Memorias de Norte.

Memorias de MZA.

Revista Nacional de Economía.

\section{BIBLIOGRAFIA}

ANDREWS, F. (2000): «Employement on the railways in east Kent, 1841-1914», The Journal of Transport History, 21, I, pp. 54-70.

ANES, R. (1978): «Relaciones entre el ferrocarril y la economía», en M. ARTOLA (dir.) (1978), Los ferrocarriles en España, 1844-1943, vol. 2, Madrid, Banco de España, pp. 355-512.

Anuario General de España (1921), Madrid, Baylle-Baillieri.

Asociacion General de Transportes por via Terrestre (1935): Tres años de politica ferroviaria. Memoria de la actuación de esta entidad rendida por el consejero dele gado D. Blas Vives, Madrid.

Artol A, M. (1978): «La acción del Estado», en M. ArTOLA (dir.) (1978), Los ferrocarriles en España, 1844-1943, vol. 1, Madrid, Banco de España, pp. 341-453.

A $\approx \Lambda$ (1918): «El recargo de las tarifas ferroviarias», en Revista Nacional de Economía, núm. 14, pp. 68-72.

Boletin de la Arociacion General de Transportes por Via Férrea (1933), «Proyecto de Estatuto del Personal Ferroviario», Suplemento al núm. 6.

Bores Romero, J. (1918): «Carreteras y Ferrocarriles», en Revista Nacional de Economia, núm. 16, pp. 337-355. 
Brunet, P. J. (1994): La companya dels ferrocarrils de Mallorca, Palma de Mallorca, Conselleria de Cultura, Educació i Esports.

CANALES, S. (1912): La buelga de los ferrocarriles, Madrid.

CARreras, A. (1990): Industrialización española: estudios de bistoria cuantitativa, Madrid, Espasa-Calpe.

Carreras, A., y TAFUnell, X. (1993): «La gran empresa en España - 1917-1974-. Una primera aproximación», en Revista de Historia Industrial, núm. 3, pp. $127-174$.

- (1996): «La gran empresa en la España contemporánea: entre el Mercado y el Estado», en Comin, F., y MARTín ACEǸA, P. (1996), La Empresa en la Historia de España, Madrid, Civitas, pp. 73-92.

Cayón, R.; Gonzalez Fernandez, R., y Munoz, M. (1998): El camino del Tren. 150 Años de Infraestructura Ferroviaria, Madrid, Fundación Ferrocarriles Españoles.

Ceballos Teresi, J. G. (1932): Historia Económica, Financiera y Politica de España en el siglo XX, t. VII, Estadística: 1901-1930, Madrid, El Financiero.

Cendal Burdalo, J. J. (1998): Compañia de explotación de los Ferrocarriles de Madrid a Cáceres y Portugal y del Oeste de España, Madrid, Fundación Empresa Pública, Documento de Trabajo núm. 9804.

Comin, F.; Martin Aceña, P.; Munoz Rubio, M., y Vidal Olivares, J. (1998): 150 Años de Historia de los Ferrocarriles en España, Madrid, Anaya.

Cordero, R., y MENÉNDEz, F. (1978): «El sistema ferroviario español», en M. ARToLA (dir.) (1978), Los ferrocarriles en España, 1844-1943, Madrid, Banco de España, vol. 1, pp. 163-338.

ERdozain, P., y Mikelarena, F. (1999): «Las cifras de activos agrarios de los censos de población españoles del período 1877-1991. Un análisis crítico», en Boletín de la Asociación de Demografia Histórica, XVII-I, pp. 89-113.

GIL IBÁNEZ, S. (1978): «Un intento de homogeneización de las clasificaciones profesionales en España, 1860-1930», en Revista Internacional de Sociología, núm. 25 , pp. $7-40$.

Gomez MendozA, A. (1982): Ferrocarriles y cambio económico en España (1855-1913). Un enfoque de Nueva Historia Económica, Madrid, Alianza Editorial.

- (1989a): Ferrocarril, Industria y Mercado en la modernización de España, Madrid, Espasa-Calpe.

- (1989b): «Transporte y comunicaciones», en Estadísticas Históricas de España, siglos XIX y XX, Madrid, Fundación Banco Exterior, pp. 269-326.

Imedio Diaz, A. (1928/1929), Jomada de ocho boras en los Servicios Ferroviarios $y$ aborro de las extraordinarias, Madrid, Talleres Poligráficos.

Imedio Diaz, A. (1934), Ferrocarriles. Explotación y Legislación, Madrid, Imprenta Sáez Hermanos.

Instituto de Reformas Sociales (1913): Conflicto de obreros y empleados de las Compañias de Ferrocarriles - septiembre-octubre de 1912--, Madrid, Sucra de M. Minuesa.

- (1922): Adaptación del régimen de la jomada de 8 boras a los servicios ferroviarios, Madrid, Sobrinos de la Sucesora de M. Minuesa de los Ríos. 
Juez Gonzalo, E. P. (1992): El mundo social de los ferrocarriles españoles, 1857-1917, Madrid, Universidad Complutense, Tesis doctoral.

- (1999): «La jornada de trabajo en Ferrocarriles», en II Jomadas de Historio Económica de las Relaciones Laborales, Universidad de Sevilla, pp. 137-142.

- (2000): Los ferroviarios de las antiguas compañias (una bistoria desconocida), Gijón,

Lizana Rivas, E. (1993): El Ferrocarril Madrid a Cáceres y Portugal, y su incidencia territorial, Madrid, Universidad Complutense.

López Garcia, M. (1986): MZA. Historia de sus Estaciones, Madrid, Colegio de Ingenieros de Caminos, Canales y Puertos.

MarCo, A. (1999): El ferrocarril de Cortes a Borja. Ilusión, realidad y progreso, Borja, Centro de Estudios Borjanos, Institución «Fernando el Católico».

Maristany, E. (1905): Impresiones de un viaje por los Estados Unidos, Barcelona, Imprenta de Henrich y Cía.

- (1905/1908): La Conferencia Ferroviaria de 1905. Estudios económicos sobre la explotación comercial de los ferrocarriles españoles, Barcelona, Imprenta de Henrich y Cía. en Comandita.

Marquina, J. (1940): Compañia de los Caminos de Hierro del Norte de España (1859-1939), Madrid, Espasa-Calpe.

Martin-Gamero, A. (1891): Constitución y organización de las Compañias Ferroviarias. Carácter jurídico, condiciones y relaciones de sus empleados, Madrid, Imprenta Central de los Ferrocarriles.

Matallana, M. (1873): Manual práctico de conservación de las vias férreas. Compendio de todo lo necesario al personal subalterno encargado del servicio y vigilancia de las mismas y sus obras, Barcelona, Establecimiento Tipográfico de Narciso Ramírez y Compañía.

Ministerio de Obras Púllicas (1940): Antecedentes y datos para el estudio del problema ferroviario, vol. IV, Madrid, Ministerio de Obras Públicas.

- Antecedentes y Datos para el Estudio del Problema Ferroviario, IV, Madrid.

Munoz, M. (1995): Renfe (1941-1991): Medio siglo de Ferrocarril público, Madrid, Ediciones Luna.

MZA (1908): Reglamento Provisional de la Contabilidad de los Servicios de la Red Antigua, Madrid, Establecimiento Tipográfico Sucesores de Rivadeneyra.

- (1932): Reseña bistórica de su constitución y desarrollo. Actuación de la Compañia durante los últimos veinte años, 1913-1931, Madrid, Establecimiento Tipográfico Sucesores de Rivadeneyra.

- (1933): Ventajas diversas disfrutadas por el personal de los diferentes servicios en el ejercicio de 1933, Madrid.

- (1934): Situación del personal en la Compañia MZA (1913-1933), Madrid, Sucesores de Rivadeneyra.

- (1935a): Ventajas diversas disfrutadas por el personal de los diferentes servicios en el ejercicio de 1935, Madrid.

- (1935b): Servicio de Explotación. Instrucciones para la formación de las hojas de presencia y listas de jornales del personal de servicio, Madrid, Sucesores de Ribadeneyra.

NADAL, J. (1975): El fracaso de la revolución industrial en España, Barcelona, Ariel. 
NICOLAU, R. (1989): «Población», en Estadísticas Históricas de España. Siglos XIX $y x X$, Madrid, Fundación Banco Exterior, pp. 49-90.

NORTE (1891): Instrucción General Número 2: sobre el Personal de los Servicios de la Compañia, Madrid, Imprenta Central de los Ferrocarriles.

NORTE (1916): La Compañia del Norte y su personal. Datos y cifras que es preciso conocer para juzgar con acierto el problema ferroviario, Madrid, Imprenta Central de los Ferrocarriles.

- (1920): Estatutos del Personal -proyecto preparado por la Comisión--, Madrid, Imprenta Central de los Ferrocarriles.

Ormaechea, A. M. ${ }^{a}$ (1989): Ferrocarriles en Euskadi, 1855-1936, Bilbao, Ferrocarriles Vascos.

OrtúNeZ, P. P. (1999): El proceso de nacionalización de los Ferrocarriles en España. Historia de las grandes compañias, 1913-1943, Tesis doctoral, Facultad de Ciencias Económicas y Empresariales, Universidad de Valladolid.

Peña Boeuf, A., y Pérez Copnesa, G. (1940) (recop.): Antecedentes y datos para el estudio del problema ferroviario, Madrid, Gráficas Reunidas.

Pérez Moreda, V. (1997): «La población», Historia de España, Ramón Menéndez Pidal, t. XXXIII, Madrid, Espasa-Calpe.

Pérez Sanchez, G. (1992): «Los Talleres Principales de Reparación de la Compañía del Norte en Valladolid: un estudio de Historia Social (1861-1931)», en Investigaciones Históricas, núm. 12, pp. 252-283.

Reyer, D., y Valero Lobo, A. (1995): «Fuentes de información demográfica en España», en Cuadernos Metodológicos, núm. 13, Madrid, Centro de Investigaciones Sociológicas.

Soto Carmona, A. (1989): El trabajo industrial en la España contemporánea (1874-1936), Madrid, Anthropos.

TEDDE DE LORCA, P. (1978): «Las compañías ferroviarias en España», en ARTOLA (dir.) (1978), Los ferrocarriles en España, 1844-1943, vol. 2, Madrid, Banco de España, pp. 13-355.

TOMAs GarCia, L. J. (1991): La minería sevillana del carbón: Minas de la Reunión y la Compañia de los Ferrocarriles de MZA, Sevilla, Excma. Diputación Provincial.

TORRE, E. de la (1902): Legislación comercial de ferrocarriles, Madrid, Imprenta Central de los Ferrocarriles.

- (1922): Distancias kilométricas entre todos los empalmes y bifurcaciones: bases de percepción de las tarifas generales, mapa general de ferrocarriles, 9." ed. (1907), Imprenta Central de los Ferrocarriles.

TORTella, G. (1973): Los origenes del capitalismo en España. Banca, Industria y Ferrocarriles en el siglo XIX, Madrid, Tecnos.

Vidal Olivares, J. (1999): «La estructura de la propiedad, la organización y la gestión de una empresa ferroviaria: la Compañia de los Caminos de Hierro del Norte de España, 1858-1936», en Revista de Historia Económica, núm. 3, pp. 623-662.

WAIs, F. (1987): Historia de los Ferrocarriles Españoles, 3. ${ }^{a}$ ed., Madrid, Fundación de los Ferrocarriles Españoles. 


\section{APÉNDICE}

TABLA 1

Trabajadores del Ferrocarril de Via Ancha, 1893-1935

\begin{tabular}{|c|c|c|c|c|}
\hline Años & $A$ & $B$ & $C$ & $D$ \\
\hline $1893^{1}$. & 9.880 & 20.742 & 34.150 & 85,2 \\
\hline $1894^{2}$. & 10.085 & 32.720 & 34.598 & 84,9 \\
\hline $1895^{3}$. & 10.526 & 33.592 & 35.470 & 84,7 \\
\hline $1896^{4}$. & 10.827 & 41.153 & 42.620 & 87,5 \\
\hline ..................... & 10.883 & 42.680 & 43.203 & 85,1 \\
\hline $1898^{\circ}$. & 10.995 & 43.429 & 43.983 & 84,1 \\
\hline $1899^{7} \ldots \ldots \ldots \ldots \ldots \ldots \ldots$ & 11.039 & 43.539 & 45.032 & 82,6 \\
\hline $1900 \ldots \ldots \ldots \ldots \ldots \ldots$ & 11.190 & 44.223 & 45.850 & 82,3 \\
\hline 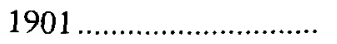 & 11.252 & 50.143 & 52.480 & 83,2 \\
\hline $1902^{8}$ & 11.269 & 51.234 & 53.571 & 83,7 \\
\hline $1903 \ldots \ldots \ldots \ldots \ldots \ldots$ & 11.309 & 52.313 & 54.650 & 83,5 \\
\hline 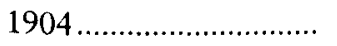 & 11.309 & 53.528 & 55.865 & 83,4 \\
\hline 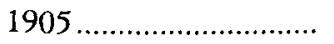 & 11.325 & 53.966 & 56.303 & 83,2 \\
\hline 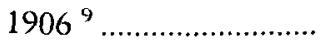 & 11.362 & 55.161 & 55.772 & 83,1 \\
\hline $1907 \ldots \ldots \ldots \ldots \ldots \ldots \ldots \ldots$ & 11.362 & 57.433 & 58.989 & 82,8 \\
\hline $1908 \ldots$ & 11.362 & 58.457 & 59.145 & 82,5 \\
\hline 1909 & 11.362 & 61.582 & 62.270 & 83,1 \\
\hline 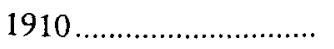 & 11.362 & 63.135 & 63.900 & 83,4 \\
\hline 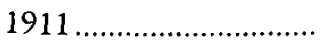 & 11.362 & 63.632 & 64.397 & 83,5 \\
\hline $1912^{10}$ & 11.381 & 64.288 & 65.053 & 83,4 \\
\hline $1913 \ldots \ldots \ldots \ldots \ldots \ldots \ldots \ldots$ & 11.424 & 66.184 & 67.806 & 83,5 \\
\hline $1914^{11} \ldots \ldots \ldots \ldots \ldots \ldots \ldots \ldots$ & 11.424 & 69.040 & 70.834 & 83,9 \\
\hline 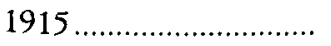 & 11.424 & 69.152 & 71.506 & 84,5 \\
\hline 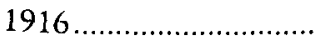 & 11.424 & 70.487 & 72.788 & 85,1 \\
\hline 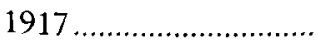 & 11.424 & 72.691 & 74.227 & 84,7 \\
\hline 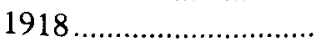 & 11.431 & 73.501 & 75.377 & 84,5 \\
\hline 1919 & 11.445 & 74.446 & 78.007 & 84,5 \\
\hline 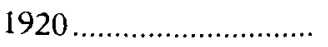 & 11.445 & 78.818 & 83.390 & 84,8 \\
\hline $1921^{12 \ldots} \ldots$ & 11.445 & 82.208 & 87.166 & 83,9 \\
\hline $1922^{13} \ldots \ldots \ldots \ldots \ldots \ldots \ldots \ldots$ & 11.482 & 87.191 & 90.231 & 84,4 \\
\hline 1923 & 11.482 & 88.287 & 91.663 & 84,2 \\
\hline $1924 \ldots \ldots \ldots \ldots \ldots \ldots \ldots \ldots \ldots \ldots$ & 11.543 & 89.044 & 94.198 & 84,1 \\
\hline 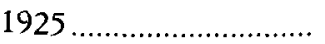 & 11.543 & 90.595 & 96.673 & 83,7 \\
\hline 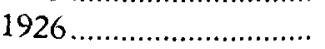 & 11.579 & 91.586 & 97.620 & 83,3 \\
\hline $1927^{14} \ldots \ldots \ldots \ldots \ldots \ldots \ldots \ldots$ & 11.667 & 99.335 & 99.762 & 83,9 \\
\hline $1928^{15}$ & 11.719 & 101.749 & 101.859 & 82,9 \\
\hline
\end{tabular}


TABLA 1 (Cont)

Trabajadores del Ferrocarril de Via Ancba, 1893-1935

\begin{tabular}{|c|c|c|c|c|}
\hline Años & $A$ & $B$ & $C$ & $D$ \\
\hline 1929 & 11.986 & 100.449 & 102.672 & 84,0 \\
\hline $1930^{16} \ldots \ldots \ldots \ldots \ldots \ldots \ldots$ & 12.030 & 104.631 & 106.602 & 83,2 \\
\hline $1931 \ldots \ldots \ldots \ldots \ldots \ldots$ & 12.030 & 101.667 & 104.778 & 84,5 \\
\hline $1932 \ldots \ldots \ldots \ldots \ldots \ldots \ldots \ldots$ & 12.030 & 101.667 & 104.671 & 84,5 \\
\hline $1933 \ldots \ldots \ldots \ldots \ldots \ldots$ & 12.228 & 106.039 & 107.945 & 83,7 \\
\hline $1934^{17} \ldots \ldots \ldots \ldots \ldots \ldots \ldots$ & 12.228 & 106.197 & 106.611 & 83,9 \\
\hline $1935 \ldots \ldots \ldots \ldots \ldots \ldots \ldots$ & 12.253 & 110.422 & 108.779 & 83,9 \\
\hline
\end{tabular}

A: Kilómetros. B: Trabajadores según la fuente. C: Serie rectificada. D: Porcentaje de las cuatro compañias principales - Norte, MZA y Red catalana y Andaluces- sobre el total sin rectificar.

1 Incluye: Compañía de los Ferrocarriles de Madrid a Zaragoza y a Alicante; Compañía de los Ferrocarriles de Tarragona, Barcelona y Francia; Compañia de los Ferrocarriles Andaluces; Compañía de los Ferrocarriles de Medina del Campo a Zamora y de Orense a Vigo; Compañía de los Ferrocarriles de Salamanca a la Frontera Portuguesa, y Compañía de los Ferrocarriles de Zafra a Huelva.

${ }^{2}$ Se incorporan: Compañía de los Caminos de Hierro del Norte de España (1893); Compañía de los Ferrocarriles Madrid, Cáceres y Portugal (1893); Compañía de los Ferrocarriles de Alcantarilla a Lorca (1893), y Compañía de los Ferrocarriles de Bilbao a Portugalete.

${ }^{3}$ Se incorpora: Compañía de los Ferrocarriles de Santiago a Carril (1893).

${ }^{4}$ Se incorpora: Compañía de los Ferrocarriles de Bobadilla a Algeciras (1893 —en 1913 es absorbida por Andaluces--).

5 Se incorporan: Compañía de los Ferrocarriles de Lorca a Baza y ramal de Águilas (1893); Compañía de los Ferrocarriles de Soria -a Alcuneza-- (1893); Compañía de los Ferrocarriles de Sevilla a Alcalá y Carmona (1893); Compañía de los Ferrocarriles de Triano -Desierto a San Juan de Musques- (1893), y Compañía de los Ferrocarriles de Sarria a Barcelona (1893).

' Se incorpora: Compañia de los Ferrocarriles de Medina de Campo a Salamanca (1893).

7 Se incorpora: Compañia de los Ferrocarriles de Valencia y Aragón (1893).

${ }^{8}$ Se incorpora: Compañía de Ferrocarriles de Mollet a Caldas de Montbuy.

9 Se incorpora: Compañia de los Ferrocarriles Central de Aragón-Calatayud, Teruel y Valencia, aunque fue adjudicado por Norte en 1927 siempre se le trató como una empresa independiente - (1901) y Sur de España - Linares a Almería- (1899).

10 Se incorpora: Compañia de los Ferrocarriles de Puebla de Hijar a Alcañiz.

11 Se incorpora: Compañía de los Ferrocarriles de Puerto de Santa Maria a San Lúcar de Barrameda.

${ }^{12}$ Se incorporan: Ferrocarriles de Cataluña - Barcelona a Tarrasa - y Compañia Internacional de Coches-Cama — compañía internacional que contrata los servicios de las compañias del país.

13 Se incorporan: Compañia de Ferrocarriles de Ripoll a Puigcerdá, de Ávila a Salamanca, y Compañía de los Ferrocarriles de Betanzos al Ferrol, líneas las dos últimas que terminará el Estado años después. 
${ }^{14}$ Se incorpora: Compañía de los Ferrocarriles de Granada a Baza. Las líneas de Zaragoza al Mediterráneo, sección de Puebla de Hijar a Alcañiz, Lérida a Balaguer, Betanzos a Ferrol y Ávila a Salamanca, ya incautadas y explotadas por el Estado debido a los graves problemas que arrastraban, pasan ahora a depender de Jefatura de Explotación de Ferrocarriles del Estado, un organismo nuevo creado en 1926. A partir de ahora sus datos no aparecen ya desagregados.

${ }^{15}$ Se incorpora: Compañía de Ferrocarriles Santander-Mediterráneo - Secciones de Burgos a Soria y Peñahorada-. Este año se constituye la Compañía de los Ferrocarriles del Oeste de España, que pasa a integrar las siguientes lineas: Madrid a Cáceres y Portugal, Ramal de Arroyo a Cáceres, Plasencia a Astorga, Ávila a Salamanca, Salamanca a Fuentes de Oñoro, Fuentes de San Esteban a Barca de Alba, Medina del Campo a Salamanca, Medina del Campo a Zamora, Monforte a Orense, Orense a Vigo y Puerto, Redondela a Pontevedra, Ramal de Guilarey al Río Miño, Pontevedra a Carril y Santiago y Betanzos a Ferrol [Revista de Obras Públicas (1928), núm. 2510, p. 351]. Desde ahora la información ya no aparece desglosada.

16 Se incorpora: Ferrocarril de Villacañas a Quintanar de la Orden, este ferrocarril empezó a funcionar en 1907, siendo de vía estrecha, pero en 1927 se transformó en vía normal, Wais (1987, II, p. 33).

17 Los Ferrocarriles de Sevilla a Alcalá y Carmona y de Murcia a Mula y Caravaca pasan a depender del Estado.

Fuentes: Anuario de los Ferrocarriles (1893-1935). Los datos sobre el kilometraje se han tomado de Gómez Mendoza (1989, pp. 282-283), aunque básicamente los datos coinciden con los que proporciona el Anuario.

TABLA 2

Trabajadores del Ferrocarril de Vía Estrecha, 1893-1935

\begin{tabular}{|c|c|c|c|}
\hline Años & $A$ & $B$ & $C$ \\
\hline $1893^{1}$. & 1.692 & 853 & 2.119 \\
\hline $1894^{2}$ & 1.841 & 1.437 & 2.541 \\
\hline $1895^{3} \ldots \ldots \ldots \ldots \ldots$ & 1.853 & 2.281 & 3.438 \\
\hline 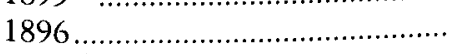 & 1.968 & 2.379 & 3.535 \\
\hline $1897^{4}$ & 1.972 & 3.750 & 4.650 \\
\hline $18985 \ldots \ldots \ldots \ldots$ & 1.965 & 4.285 & 4.885 \\
\hline $1899^{6} \ldots \ldots \ldots \ldots$ & 2.016 & 4.362 & 4.890 \\
\hline $1900^{7}$ & 2.042 & 4.335 & 4.933 \\
\hline $1901^{8} \ldots \ldots \ldots \ldots \ldots$ & 2.102 & 4.839 & 5.164 \\
\hline 1902 & 2.117 & 5.027 & 5.406 \\
\hline $1903^{9} \ldots \ldots \ldots \ldots$ & 2.311 & 5.183 & 5.442 \\
\hline $1904 \ldots \ldots$ & 2.582 & 5.378 & 5.637 \\
\hline $1905^{10}$ & 2.972 & 5.557 & 5.816 \\
\hline $1906^{11} \ldots \ldots \ldots \ldots$ & 3.009 & 6.178 & 6.500 \\
\hline $1907 \ldots \ldots \ldots \ldots$ & 3.060 & 6.378 & 6.574 \\
\hline $1908^{12}$ & 3.103 & 6.957 & 7.169 \\
\hline $1909 \ldots \ldots \ldots \ldots \ldots$ & 3.173 & 7.063 & 7.468 \\
\hline
\end{tabular}


TABLA 2 (Cont.)

Trabajadores del Ferrocarril de Via Estrecha, 1893-1935

\begin{tabular}{|c|c|c|c|}
\hline$A \bar{n} o s$ & $A$ & $B$ & C \\
\hline $1910^{13}$. & 3.223 & 7.259 & 7.587 \\
\hline $1911^{14}$. & 3.326 & 7.699 & 7.920 \\
\hline $1912^{15}$. & 3.546 & 8.019 & 8.782 \\
\hline 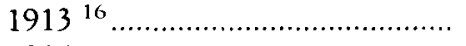 & 3.608 & 8.466 & 9.057 \\
\hline 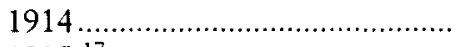 & 3.698 & 8.789 & 9.529 \\
\hline $1915^{17}$. & 4.006 & 8.961 & 9.572 \\
\hline $1916^{18}$. & 4.065 & 9.654 & 10.165 \\
\hline 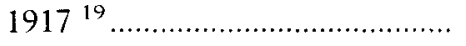 & 4.108 & 10.470 & 11.179 \\
\hline 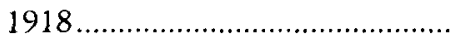 & 4.180 & 10.760 & 11.469 \\
\hline 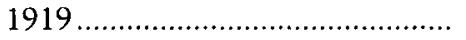 & 4.198 & 10.833 & 11.542 \\
\hline 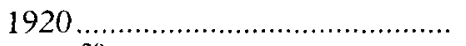 & 4.312 & 10.924 & 11.633 \\
\hline 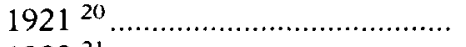 & 4.326 & 11.915 & 12.213 \\
\hline $1922^{21}$. & 4.391 & 11.918 & 12.295 \\
\hline $1923^{22} \ldots$ & 4.413 & 12.712 & 12.920 \\
\hline 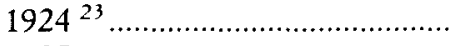 & 4.404 & 12.746 & 12.954 \\
\hline 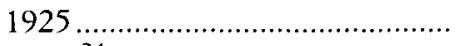 & 4.449 & 13.483 & 13.691 \\
\hline 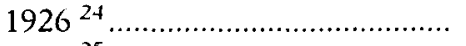 & 4.452 & 14.002 & 14.487 \\
\hline 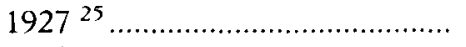 & 4.598 & 14.377 & 14.862 \\
\hline 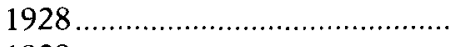 & 4.598 & 14.631 & 15.341 \\
\hline 1929 & 4.598 & 14.792 & 15.304 \\
\hline 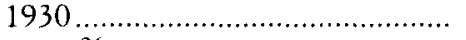 & 4.573 & 14.798 & 15.343 \\
\hline 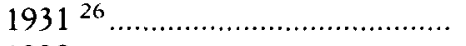 & 4.573 & 14.966 & 15.655 \\
\hline 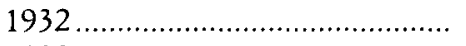 & 4.573 & 14.981 & 15.676 \\
\hline 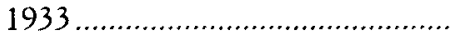 & 4.570 & 15.692 & 15.670 \\
\hline 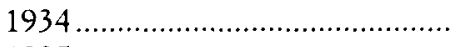 & 4.544 & 15.633 & 16.481 \\
\hline 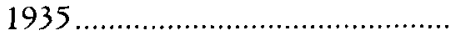 & 4.550 & 15.444 & 16.284 \\
\hline
\end{tabular}

A: Kilómetros. B: Trabajadores según la fuente. C: Serie rectificada.

1 Incluye: Ferrocarril de Durango a Zumárraga; Ferrocarril de Bilbao a Durango (Central de Bilbao); Ferrocarril de Cariñena a Zaragoza y Ferrocarriles de Oviedo a Infiesto (Económicos de Asturias).

2 Se incorporan: Ferrocarril de Silla a Cullera (1893); Ferrocarril de Langreo y Ferrocarril de San Feliú de Guixols a Gerona (1893).

${ }^{3}$ Se incorporan: Ferrocarril de Bilbao a Las Arenas; Ferrocarril de la Robla a Valmaseda (1893) y Ferrocarril Anglo-Vasco-Navarro (1893).

4 Se incorporan: Ferrocarril de Las Arenas a Plencia: Ferrocarril de Alcoy a Gandía y Puerto de Gandía (1893); Ferrocarril de Amorobieta, Guernica y Pedernales (1893); Ferrocarril de Flassá a Palamós; Ferrocarril de Olot a Gerona (1893); Ferrocarril de Bilbao a Lezama (1895); Ferrocarril de Santander a Bilbao; Ferrocarril de Penarroya a Fuente del Arco; Ferrocarril de Valladolid a Medina de Rioseco; Ferrocarril de Madrid a Villa del Prado (en 1930 incautado por el Estado); Ferrocarril del Cantábrico (Santander a Cabezón de la Sal); Ferrocarril de Cortes a Borja (1893). También es esta fecha se incorpora a 
los Ferrocarriles Vascos el de Elgóibar a San Sebastián y el ramal de Durango a Arrazola y Elorrio (hasta 1901 no comienza la explotación de la línea completa).

5 Se incorporan: Sociedad de Tranvías de Valencia (sección de ferrocarril) (1893); Ferrocarril del Tajuña («Madrid-Aragón») y Ferrocarril de Buitrón a Zalamea y San Juan del Puerto.

- Se incorporan: Ferrocarril Central Catalán (Igualada a Martorell) y Ferrocarril de Onda al Grao de Castellón de la Plana (1893).

7 Se incorpora: Ferrocarriles de Villena a Alcoy y Yecla (1893).

Se incorpora: Ferrocarriles del Grao de Valencia a Turis (de Valencia a Alberique) (1893).

${ }^{9}$ Se incorpora: Ferrocarril de Manresa a Berga (1893). Los Ferrocarriles de Bilbao a Durango, Durango a Zumárraga y Elgóibar y Elgóibar a San Sebastián se integran desde ahora los Ferrocarriles Vascongados.

10 Se incorpora: Ferrocarril de Astillero a Ontaneda.

11 Se incorporan: Ferrocarril de Utrillas a Zaragoza y Ferrocarril de Mollerusa a Balaguer.

12 Se incorporan: Ferrocarril de Reus a Salou (1903); Ferrocarril Vasco-Asturiano; Ferro carriles de Minas de Cala a San Juan de Aznalfarache y Ferrocarriles de Luchana a Munguía (1898).

${ }^{13}$ Se incorpora: Ferrocarriles de Valdepeñas a Puertollano.

14 Se incorpora: Puertollano a Almodóvar y San Quintin Palma a Manacor, de Palma [(1993) en 1893 ya funcionaban las líneas de Paima a Inca, de la red hasta 1916, en que a la Pobla y de Santa María-Felanitx, y

se abre el trayecto de Palma a Llucmayor].

15 Se incorporan: Ferrocarril de San Sebastián a la Frontera Esteban de Pravia, y Ferrode Málaga (1908); Compañía Vasco-Asturiana

carril de Villacañas a Quintanar de la Orden.

16 Se incorpora: Ferrocarril de Barcelona a Maiz-Sangüesa.

Se incorpora: Ferrocarril de Alicante a Villajoyosa y Denia y Ferrocarril de Irún a Elizondo.

19 Se incorporan: Ferrocarriles de Haro a Ezcaray y Ferrocarriles de Sádaba a Gallur.

Ferrocarriles de Aznalcóllar al Río Guadalquivir (1908); Ferrocarril Ferrocarriles de Bilbao a Lezama (1895); Ferrocarril de San Sebastián Ferrocarril de cremallera, Monistrol a Montserrat (1893).

21 Se incorpora: Ferrocarriles de Linares a la Carolina y prolongaciones (1915). En los Ferrocarriles Catalanes se incluyen los ya citados el Ferrocarril de Manresa a Olván y Guardiola, el Ferrocarril de Igualada a Martorell y el Ferrocarril de Barcelona a Martorell y Manresa más el Ferrocarril de Suria a Manresa alta y el Ferrocarril de Bordeta al perrocaril de 22 Se incorporan: Ferrocarril de Ponferrada a Villablino Igueldo (funicular), y Ferrocarril al río Odiel (1909); Ferrocarril de San Sebastián al Monte lguedd de Guadiola a Castellar d'en Huch.

23 Se incorpora: Ferrocarril de Pamplona a Plazaola, Andoain y Lasarte.

${ }^{24}$ Se incorporan: Ferrocarril de Zumárraga a Zumaya y Ferrocarriles de Carreño.

${ }^{25}$ Se incorporan: Bajo la Jefatura de Explotación de Ferrocarriles —organismo recién creado (RD de 3 julio de 1926) - se incluyen, además de los ya mencionados de Amorobieta a Guernica, Vasco-Navarro y de Valdepeñas a Puertollano, el de Madrid a Villar del Prado y Almorox, el de Vitoria a Mecolalde y Estella, el el Castro Urdiales a Traslaviña, el de Cartagena a los Blancos y el de Málaga a Fuengirola.

Se incorpora: Ferrocarril de Calahorra a Arnedillo (1921).

Fuevte Anuario de los Ferrocarriles, 1893-1930. La columna A no coincide con los datos de Gómez Mendoza (1989b, pp. 282-284), quien toma como fuente desde 1914 el Anuario Estadístico de España. 